\title{
Validation and empirical correction of MODIS AOT and AE over ocean
}

\author{
N. A. J. Schutgens ${ }^{1}$, M. Nakata ${ }^{2}$, and T. Nakajima ${ }^{3}$ \\ ${ }^{1}$ Atmospheric, Oceanic and Planetary Physics, University of Oxford, Oxford, UK \\ ${ }^{2}$ Faculty of Applied Sociology, Environmental Studies, Kinki University, higashi-Osaka, Japan \\ ${ }^{3}$ Atmospheric and Oceanic Research Institute, University of Tokyo, Tokyo, Japan
}

Correspondence to: N. A. J. Schutgens (schutgens@physics.ox.ac.uk)

Received: 8 March 2013 - Published in Atmos. Meas. Tech. Discuss.: 15 April 2013

Revised: 1 August 2013 - Accepted: 2 August 2013 - Published: 23 September 2013

\begin{abstract}
We present a validation study of Collection 5 MODIS level 2 Aqua and Terra AOT (aerosol optical thickness) and AE (Ångström exponent) over ocean by comparison to coastal and island AERONET (AErosol RObotic NETwork) sites for the years 2003-2009. We show that MODIS (MODerate-resolution Imaging Spectroradiometer) AOT exhibits significant biases due to wind speed and cloudiness of the observed scene, while MODIS AE, although overall unbiased, exhibits less spatial contrast on global scales than the AERONET observations. The same behaviour can be seen when MODIS AOT is compared against Maritime Aerosol Network (MAN) data, suggesting that the spatial coverage of our datasets does not preclude global conclusions. Thus, we develop empirical correction formulae for MODIS AOT and AE that significantly improve agreement of MODIS and AERONET observations. We show these correction formulae to be robust. Finally, we study random errors in the corrected MODIS AOT and AE and show that they mainly depend on AOT itself, although small contributions are present due to wind speed and cloud fraction in AOT random errors and due to $\mathrm{AE}$ and cloud fraction in $\mathrm{AE}$ random errors. Our analysis yields significantly higher random AOT errors than the official MODIS error estimate $(0.03+0.05 \tau)$, while random AE errors are smaller than might be expected. This new dataset of bias-corrected MODIS AOT and AE over ocean is intended for aerosol model validation and assimilation studies, but also has consequences as a stand-alone observational product. For instance, the corrected dataset suggests that much less fine mode aerosol is transported across the Pacific and Atlantic oceans.
\end{abstract}

\section{Introduction}

Aerosols affect the Earth's radiation budget, either through scattering and absorption of direct sunlight or through modification of cloud parameters. At the moment, aerosols are considered the dominant uncertainty in radiative forcing estimates for the Earth's atmosphere. They are especially interesting because their general impact seems to be a cooling of the atmosphere and because they may actually slow down warming by greenhouse gases on regional scales.

To increase our understanding of the aerosol system, major efforts to observe it have been launched in the past two decades. Although our most reliable observations come from ground-based observing networks (e.g. the AERONET ${ }^{1}$ sun photometers), substantial spatial coverage can only be achieved through satellite observations. One of the best known satellite datasets of aerosol observations are formed by the observations of the two MODIS ${ }^{2}$ sensors aboard the Aqua (local Equator crossing time of 13:30) and Terra (local Equator crossing time of 10:30) satellites. These sensors fly at an altitude of $705 \mathrm{~km}$ and have a cross-track view of $2330 \mathrm{~km}$. They observe the earth in 36 different spectral bands, of which several bands in the visual and near-infrared are suited to aerosol retrievals.

The MODIS observations of aerosol are based on lookup tables that allow retrieval of multi-wavelength $\mathrm{AOT}^{3}$ from measured radiances (Tanre et al., 1997). To produce these lookup tables, assumptions on e.g. surface reflection and

\footnotetext{
${ }^{1}$ AERONET: AErosol RObotic NETwork.

${ }^{2}$ MODIS: MODerate-resolution Imaging Spectroradiometer.

${ }^{3}$ AOT: aerosol optical thickness.
} 
aerosol chemical composition are made. The observations have been validated through comparison with the AERONET ground-based network observations (Ichoku et al., 2002, 2005a; Remer et al., 2002, 2005, 2008; Bréon et al., 2011). Additional products like fine mode fraction (fine mode AOT divided by total AOT) have been evaluated by Anderson et al. (2005), Kleidman et al. (2005) and Bréon et al. (2011) and the aerosol effective size by Remer et al. (2002) and Remer et al. (2005). For a comparison to the Maritime Aerosol Network (MAN) data (see Smirnov et al., 2011; Adames et al., 2011). The main conclusion from these papers is that MODIS level 2 AOT over ocean shows significant correlation with AERONET observations. Nevertheless, substantial random errors exist. Also, MODIS AOT seems to be biased high for low AOT and low for high AOT. Fine mode fraction and effective particle size generally show lower correlation with AERONET than AOT.

Although these papers studied MODIS observational biases and random errors, no attempt was made to develop error models that would predict such errors as a function of independent variables like viewing angle, wind speed or cloud fraction. A single bias and random error were instead specified for all available data.

However, it is likely that MODIS biases and random errors vary with the observed scene; an example would be random errors in the fine mode fraction that can be expected to decrease with increasing AOT. It has been shown that under cloudy conditions or when wind speeds are high, MODIS tends to overestimate AOT over ocean compared to AERONET (Zhang and Reid, 2006; Shi et al., 2011). Quantification and, hopefully, correction of these biases is important for data assimilation purposes, where unbiased observations are used to "nudge" a model closer to the observed atmospheric state. In addition to assimilation, unbiased observations serve an obvious purpose in validation efforts of aerosol transport models.

Zhang and Reid (2006) and Shi et al. (2011) developed empirical correction formulae for MODIS AOT over ocean through systematic comparison with AERONET observations. These formulae use supplementary data on surface wind fields, cloud coverage and aerosol fine mode fraction. Hyer et al. (2011) have developed additional screening procedures and correction formulae that reduce AOT errors over land.

Previous efforts at correcting MODIS observational biases have focused on AOT. However, $\mathrm{AE}^{4}$ contains a lot of useful information on the aerosol system as it typically tracks particle size. Even though this interpretation may be ambiguous in the case of multi-modal aerosol size distributions, the use of observation operators (functions that map atmospheric distributions of aerosol to observables like AOT or AE) allows meaningful application of AE observations in the context of either assimilation or model validation. In MODIS

\footnotetext{
${ }^{4} \mathrm{AE}:$ Ångström exponent.
}

studies, fine mode fraction is often used instead of AE, but Anderson et al. (2005) argued that validation of AE is more straightforward and should therefor be preferred. We see a few additional advantages of using AE over fine mode AOT or fraction: $\mathrm{AE}$ has a simple definition (see Eq. 1 further on) in contrast to fine mode fraction; AE potentially allows for AOT errors to balance out, due to the division of AOT at different wavelengths (again, see Eq. 1); and AE errors and AOT errors are uncorrelated. The last point is very obvious in the dataset we will work with in this paper, where AOT errors at different wavelengths are strongly correlated while AOT errors and AE errors are not. Uncorrelated errors will simplify the construction of empirical corrections and make assimilation of the observations easier.

In this paper, we validate Collection (Coll.) 5 MODIS level 2 AOT and AE observations against AERONET and the Maritime Aerosol Network. Given the very similar results, we conclude that AERONET spatial sampling does not substantially influence the validation of MODIS observations. Thus, we develop correction formulae for MODIS AOT and AE by regressing MODIS observations against AERONET observations. For the corrected MODIS AOT and AE, we develop simple models that describe the remaining random errors. In Table 1, we present the major differences between our analysis and the analyses by Zhang and Reid (2006) and Shi et al. (2011). The main differences are that we (1) validate and correct MODIS AE observations (in addition to AOT); (2) corroborate our analysis with Maritime Aerosol Network data; and (3) sub-sample our data to create a set of independent MODIS errors (this will be shown to affect biases).

In Sect. 2, we introduce the three datasets that we will use in our analysis. Section 3 describes how we select the colocated MODIS-AERONET observations that will be used for validation of the original MODIS product. This validation is presented in Sect. 4 together with corroborative evidence from the Maritime Aerosol Network. In Sect. 5, we explain how one may derive correction formulae for both MODIS AOT and AE. The robustness of that correction is also discussed. The global impact of our correction on AOT and $\mathrm{AE}$ observations over ocean is shown in Sect. 6, while the remaining random errors in $\mathrm{AOT}$ and $\mathrm{AE}$ are discussed in Sect. 7.

In this paper, we will call the difference between colocated MODIS and AERONET AOT observations the MODIS AOT error. We assume that AERONET represents the truth or at least that its errors are negligible compared to MODIS. MODIS will experience the same error when observing under identical circumstances, but any arbitrary set of MODIS observations will have an error distribution. If this distribution is Gaussian and perfectly known, we can determine a bias (the mean of the distribution) and a random error (the standard deviation). In reality, the distribution is only near-Gaussian, of finite size, and with many outliers. So we have chosen to use the median (or the $50 \%$ quantile) to define 
Table 1. Comparison between three relevant studies.

\begin{tabular}{llll}
\hline & Zhang and Reid (2006) & Shi et al. (2011) & This paper \\
\hline Period & Aqua: Sep 2004-Aug 2005 & Aqua: 2002-2008 & Aqua: 2003-2009 \\
& Terra: 2004 & Terra: 2000-2008 & Terra: 2003-2009 \\
Collection & 4 & 5 & 5 \\
MODIS & AOT at 470, 550 and $860 \mathrm{~nm}$ & AOT at $550 \mathrm{~nm}$ & AOT at $550 \mathrm{~nm}$ \\
& & & AE at $860 / 470 \mathrm{~nm}$ \\
AERONET & level 1.5 & level 2.0 & level 2.0 \\
Maritime Aerosol Network & no & no & yes \\
Co-location & $0.3^{\circ}, 20^{m}$ & $0.3^{\circ}, 30^{m}$ & $50 \mathrm{~km}, 30^{m}$ \\
Wind speeds & NOGAPS & NOGAPS & NCEP-DOE-II \\
Dataset & full dataset & full dataset & independent sub-sample \\
\hline
\end{tabular}

bias and half the interquantile range from 15.8 to $84.2 \%$ to define the random error (note this is the mean and standard deviation in case of a Gaussian distribution). Statistical properties based on quantiles are more robust in the presence of outliers than the mean and standard deviation (see also Sect. 7). Note, by the way, that the bias can be negative. In that case, it will be said to decrease when it becomes even more negative.

Several figures in the paper show box-whisker plots that use a common interpretation. First, the sample was binned according to some variable, e.g. wind speed. Next, the 10, 25, 50, 75 and $90 \%$ quantiles of the MODIS error were determined per bin. Finally, this distribution is represented in a box-whisker plot. The open vertical bar shows the interquantile range $(25-75 \%)$ and the vertical lines extending from this open bar the 10 to $90 \%$ interquantile range. The median is shown by the horizontal line inside the open bar. This median is surrounded by a solid bar (narrower than the open bar) that gives the 5 to $95 \%$ interquantile range of the median estimates according to a bootstrap analysis. Finally, on top of each bar a numerical value gives the number of observations per bin, either in counts (integers) or percentages (decimals) of the total.

\section{MODIS, AERONET and NCEP-DOE-II data}

We will use the following datasets: Coll. 5 MODIS Aqua and Terra level 2 data, AERONET level 2.0 from the version 2 direct sun algorithm, Maritime Aerosol Network level 2.0 and NCEP-DOE-II ${ }^{5}$ 6-hourly reanalysis of wind speeds, temperature and specific humidity. Data from 2003 (2004 for maritime AERONET) up to and including 2009 were downloaded from their respective websites.

The MODIS Coll. 5 level 2 data were downloaded from www.modis.gsfc.nasa.gov/. We will use the "average ocean"

\footnotetext{
${ }^{5}$ NCEP-DOE: National Centers for Environmental Prediction, Department Of Energy.
}

AOT product at 470, 550 and $860 \mathrm{~nm}$ (Remer et al., 2005). AOT at 470 and $860 \mathrm{~nm}$ is converted into an Ångström exponent through

$\alpha=-\frac{\log \tau_{2} / \tau_{1}}{\log \lambda_{2} / \lambda_{1}}$,

where $\tau$ and $\lambda$ represent AOT and wavelength as usual. In addition, we will use supplementary data provided in the MODIS data product such as the observed cloud fraction and the various scattering geometry angles (viewing zenith angle, solar zenith angle, etc.). MODIS pixels in the aerosol product have a 10 by $10 \mathrm{~km}$ size sub-satellite but this increases to around 40 by $20 \mathrm{~km}$ near the edges of the swath. All data over ocean will be used, irrespectively of QA (quality assurance) flag, as recommended by Remer et al. (2005) (see also Mishchenko et al., 2010). The MODIS AOT random error over ocean is often taken to be

$\Delta \tau=0.03+0.05 \tau$,

see e.g. Remer et al. (2005).

AERONET data (Holben et al., 1998) were downloaded from www.aeronet.gsfc.nasa.gov/ and contain AOT at various wavelengths $(440,550,675$ and 870) derived from the direct sun algorithm. These AOT are converted into AOT at $550 \mathrm{~nm}$ (if not directly observed) and AE for $870 / 440 \mathrm{~nm}$, in both cases using Eq. (1), for later comparison to MODIS. AERONET AOT errors are estimated to be $\sim 0.01$ (Eck et al., 1999; Schmid et al., 1999) and we will use AERONET as a reference to which MODIS may be compared. Not all AERONET sites, however, will be used as some may be less representative than others for comparison to MODIS satellite observations (see Sect. 5.1 for details). Although AERONET low level cloud screening is probably very good, there remain issues with cirrus clouds (Huang et al., 2011). All AERONET observations were averaged over $1 \mathrm{~h}$, every hour.

Maritime Aerosol Network data (Smirnov et al., 2011) were downloaded from www.aeronet.gsfc.nasa.gov/. 
Smirnov et al. (2011) estimate AOT errors to be $\sim 0.02$. No further screening was applied to these data, as they were only used for additional verification.

The NCEP-DOE-II reanalysis data (www.esrl.noaa.gov/) are the 6-hourly values for surface pressure, air temperature at $2 \mathrm{~m}$, specific humidity at $2 \mathrm{~m}$ as well as wind speeds at $10 \mathrm{~m}$ at a global Gaussian T62 grid. This reanalysis (Kanamitsu et al., 2002) is an improved version of the original NCEP reanalysis (Kalnay et al., 1996). The NCEP-DOE-II data were linearly interpolated to the location and time of the MODIS pixel.

\section{MODIS data screening}

\subsection{Common sense quality control criteria}

We will start by screening the complete MODIS observational dataset using the same rules of thumb that Zhang and Reid (2006) proposed and Shi et al. (2011) used. The purpose of this screening is to remove observations that are more error-prone than usual. We will discard any observation with AOT $>3$, as radiances tend to saturate beyond this value ( $\sim 0.02 \%$ of data is lost). We will also discard any observation with a cloud fraction larger than $0.8(\sim 27 \%$ of data is discarded). Zhang and Reid (2006) found increased differences between MODIS and AERONET AOT for large cloud fractions and Liu and Pinker (2008) found significant less correlation among MODIS and MISR (Multi-angle Imaging Spectroradiometer) AOT for cloud fractions above 0.8. We also discard any observation that is isolated, i.e. does not have at least one neighbour ( $\sim 1 \%$ of data is discarded). Finally, we discard observations that show too much spatial variation (defined as the standard deviation across a set of 3 by 3 MODIS pixels). Our hope is that the latter two criteria will eliminate the worst cases of cloud-contaminated observations, but undoubtably good observations with strong spatial AOT gradients will be removed as well. A typical standard deviation across a 3 by 3 MODIS pixel is determined as a function of AOT. Typically, this standard deviation increases as AOT increases (see Fig. 8 in Zhang and Reid, 2006, or Fig. 2 in Shi et al., 2011). By discarding those pixels that have a standard deviation larger than 1 times the typical value, we remove the pixels with the strongest spatial gradients ( $\sim 14 \%$ of data is discarded). Note that Zhang and Reid (2006) and Shi et al. (2011) use 1.5 times the typical value as criterium. Zhang and Reid (2006) and Shi et al. (2011) allowed some observations observed within the sun glint angle $\theta>30^{\circ}$, but we only allow pixels outside the glint angle $\left(\theta>40^{\circ}\right)$.

\subsection{Co-location of MODIS and AERONET observations}

After screening the MODIS observations in the manner described above, we co-locate them with AERONET

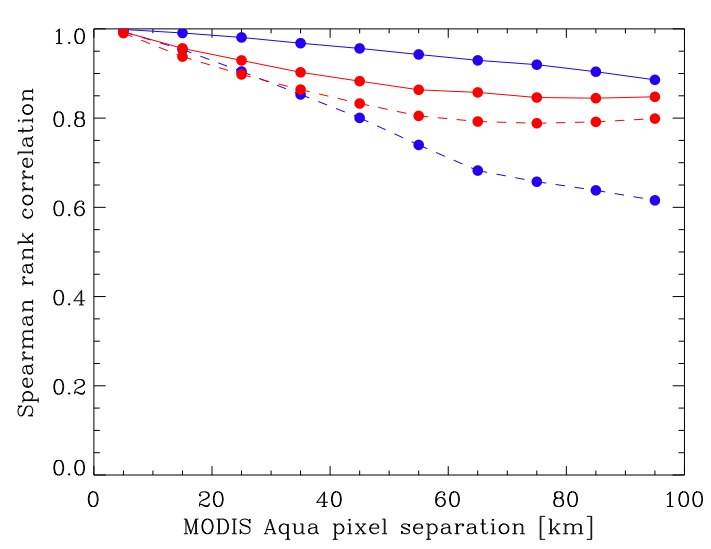

Fig. 1. Spatial correlations among two arbitrary MODIS observations (solid blue: AOT, solid red: AE) or their errors (dashed) as a function of spatial separation. Only MODIS observations colocated with AERONET were used.

observations. Any MODIS observation within $50 \mathrm{~km}$ and within $30 \mathrm{~min}$ of an AERONET observation (1 h averages, see Sect. 2) is considered co-located. We varied these criteria within reasonable bounds and concluded that, for the above values, correlation among MODIS and AERONET AOT at $550 \mathrm{~nm}$ is maximal. This agrees well with other studies (Ichoku et al., 2002; Bréon et al., 2011). Because of this co-location criterium, several individual MODIS observations will be co-located with the same AERONET observation. On average, every AERONET observation is co-located with 10 MODIS observations, although the actual number varies between 1 and 76 .

\subsection{Spatial correlations in MODIS observations}

Observed aerosol fields are known to exhibit correlations over tens of kilometres (Anderson et al., 2003; Kovacs, 2006; Santese et al., 2007), due to the nature of transport of aerosol particles. We expect to see such long correlation length scales in our MODIS dataset, also because our common sense quality control criteria preferentially select homogeneous scenes. If the MODIS error is dominated by retrieval assumptions, spatial correlations are likely to exist in those errors as well. In Fig. 1 we show the spatial correlation for the MODIS observations and for the errors. From all MODIS observations co-located with an AERONET observation, pairs of MODIS observations at different spatial separations were randomly chosen. By combining the results for all AERONET observations, the correlation between two MODIS pixels as a function of distance could be computed. As we constrained our co-located observations to a distance of $50 \mathrm{~km}$ from the AERONET site, the spatial separation of these MODIS pixels can never be more than $100 \mathrm{~km}$. We see that MODIS observations themselves show strong correlations over these $100 \mathrm{~km}$. This result is similar to that by Shinozuka and Redemann (2011) (their Fig. 3) for the case of long-range 
transport aerosol. The spatial correlations in MODIS errors are lower than those in AOT itself but still very substantial.

As a matter of fact, both the MODIS observations and their errors within a $50 \mathrm{~km}$ distance are strongly correlated $(r>0.8)$. This implies that nothing will be gained by using all possible co-located MODIS pixels. It will increase the sample size for the error analysis, but many entries in that sample are more or less copies. A meaningful statistical analysis requires either independent error estimates or specific corrections for the correlations in the dataset.

\subsection{Independent sub-samples of MODIS observations}

To obtain an independent sample, one only needs to subsample MODIS observations by randomly choosing a single pixel for each AERONET observation. Different strategies exist for choosing this single MODIS observation, although the observation closest to the AERONET observation seems the most logical. In this sub-section, we will discuss, as an example, the consequences for the MODIS AOT error for $0.5<$ AOT $<1.5$ for various sampling strategies (see Fig. 2).

In Fig. 2 the box and whisker on the far left (all) shows the error distribution when using all available co-located MODIS pixels. Next to it is the error distribution for a smaller but entirely random sub-sample (random). Unsurprisingly, these distributions are very similar. On the far right of the plot, MODIS errors for independent sub-samples are shown. Here we selected for each AERONET observation a single colocated MODIS pixel, either as close (CLOSEST) or as far away (FARTHEST, note that it is never more than $50 \mathrm{~km}$ away from the AERONET site) as possible. These two error distributions are also very similar but distinctly different from the distributions on the left side of the plot. The reason for this becomes clear if we consider independent sub-samples of only clear or cloudy MODIS pixels (CLEAR and CLOUDY). The CLEAR sub-sample agrees nicely with the full dataset (all), while the CLOUDY sub-sample shows even higher biases than CLOSEST. It seems that when using the full dataset, one biases the MODIS errors in favour of clear scenes. This is unsurprising as clear scenes allow more successful retrievals per AERONET observation (more co-located pixels) than cloudy scenes. Similarly, we find that independent sub-samples show smaller MODIS bias at large wind speeds $\left(>16 \mathrm{~m} \mathrm{~s}^{-1}\right.$ ) than the full dataset (not shown).

Summarizing the results from this sub-section and the previous one, we argue that it is necessary to use an independent sub-sample of MODIS-AERONET data pairs for the error analysis. Including all co-located MODIS pixels does not add more useful information; it merely increases sample size by adding copies. On the other hand, it will skew the estimated biases because depending on the scene some AERONET observations have many collocated MODIS observations and others have only a few. We want to stress that by creating an independent sub-sample, we do not alter the range over which parameters like AOT, wind speed or cloud

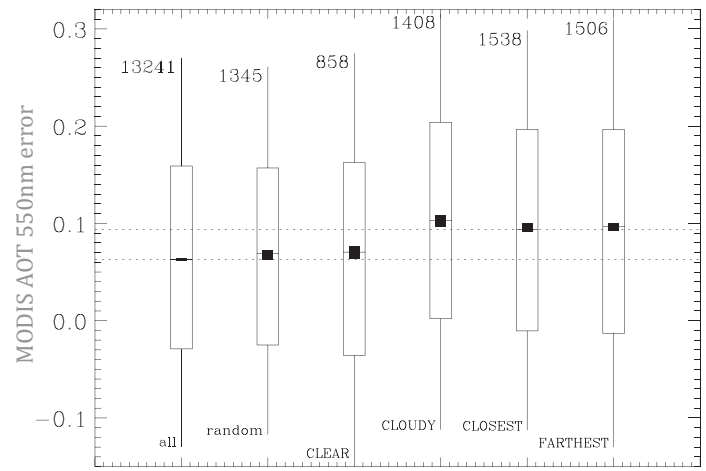

Fig. 2. MODIS Terra AOT error statistics for $0.5 \leq$ MODIS AOT $\leq 2.5$ depending on sampling strategies. The box denotes the $25-75 \%$ interquantile range and the whiskers the $10-90 \%$ interquantile range. The median is denoted by the horizontal bar in the box. The number given for each box and whisker refers to sample size.

fraction vary. We will return to the impact of different sampling strategies on MODIS errors later (in Sects. 5.3 and 5.4).

\section{Validation of MODIS AOT and AE}

\subsection{Comparison against AERONET}

In the following, we will use the independent sub-sample based on the closest MODIS observation to any AERONET observation. We will now study how AOT and AE error statistics change as a number of important parameters change. These parameters include AERONET AOT and AE, the MODIS scattering geometry angles as well as environmental variables such as wind speed, cloud fraction, temperature and relative humidity.

Figure 3 shows the main four parameters that affect MODIS AOT error statistics. They are AERONET AOT and $\mathrm{AE}$ themselves, wind speed and cloud fraction. We see that MODIS biases increase with wind speed and cloud fraction but decrease with AOT and AE. The influence of wind speed and cloud fraction on MODIS AOT bias is well known and due to limitations in the Collection 5 retrieval algorithms. The variation of the MODIS AOT bias with AE suggest that there are issues with the assumed scattering properties of the MODIS aerosol types. Note that the random errors depend mainly on AOT.

Glint angles, at least down to $40^{\circ}$ (Fig. 4), have almost no influence on error statistics, in contrast to what was reported by Zhang and Reid (2006) and Shi et al. (2011) (who allowed glint angles down to $30^{\circ}$ ). Like Ichoku et al. (2005a), we do not see a clear dependence on scattering angles (see also Mishchenko et al., 2009, who compare MODIS AOT to MISR). We do see, however, a significantly higher bias for SZA $<20^{\circ}$. Similarly, we see significantly higher biases for temperatures $T<260 \mathrm{~K}$ and relative humidities $\mathrm{RH}<0.2$. 

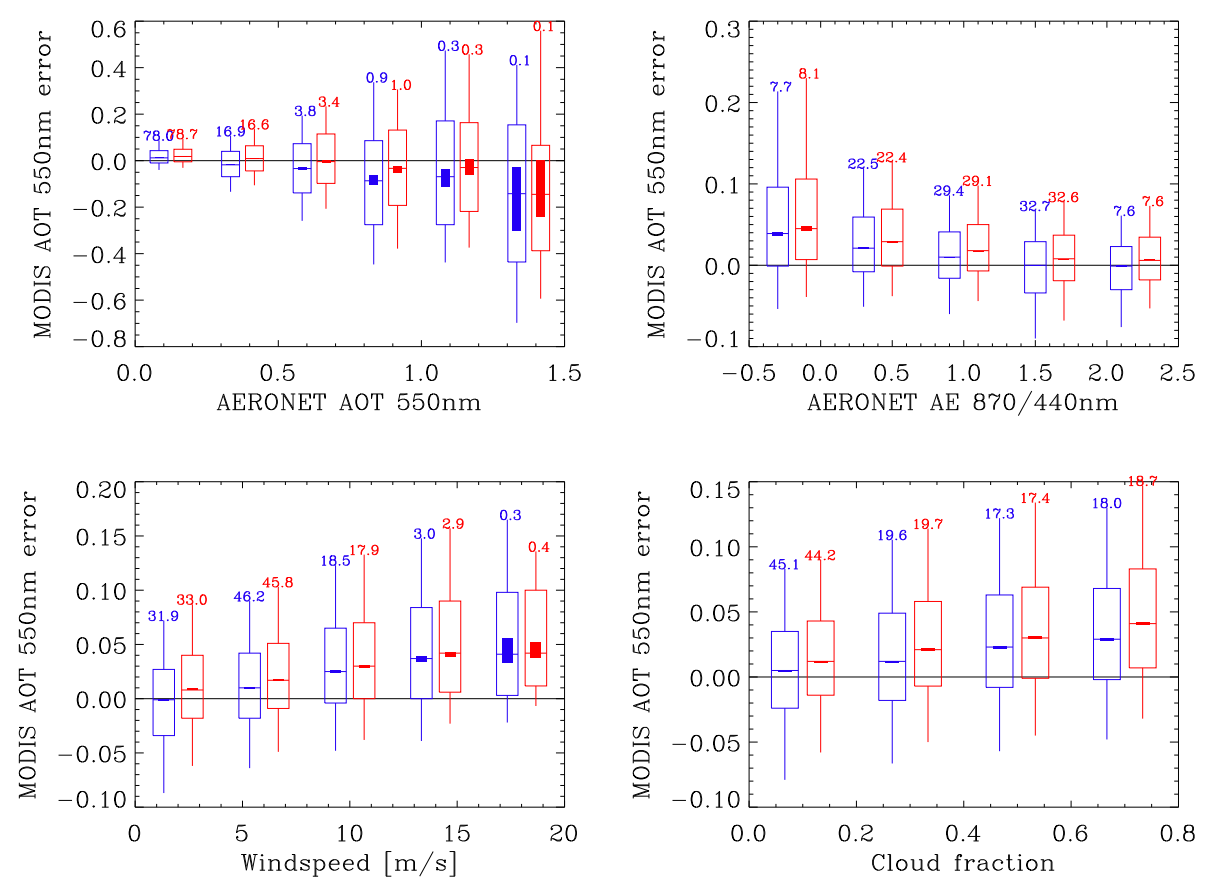

Fig. 3. MODIS AOT error statistics as a function of AERONET AOT, AERONET AE, NCEP-DOE-II wind speed and MODIS cloud fraction (blue: Aqua; red: Terra). The box-whisker plots are offset from these bin centres to show the two distributions side by side. Numbers above the box and whisker show the percentage of the total sample used in that bin.

These high biases are robust when we use different subsamples and occur only at a small number of sites, for only a few MODIS observations at each site. The bias for low temperatures may be an issue with the NCEP-DOE-II reanalysis as it only occurs for a few sites on the east coast of North America. The bias for the relative humidity may be related to the MODIS retrieval, as a correction must be made to scattering properties based on aerosol wet growth. For Aqua there is a substantial overlap between the cases with low relative humidity and low solar zenith angle, but not so for Terra.

We also found, unsurprisingly, that MODIS AOT biases increase significantly with altitude of the AERONET site (not shown). For AERONET altitudes above $300 \mathrm{~m}$ (on mountains near the coast or on islands), the collocated MODIS observed air column (over ocean) and AERONET observed air column differ substantially and the AERONET site cannot be considered representative for the MODIS observation.

Figure 5 shows the error statistics of MODIS AE. AERONET AE has a strong impact on AE biases with $\mathrm{AE}$ error positively biased for low AERONET AE and negatively biased for high AE (in agreement with Kleidman et al. , 2005, who found that the fine mode fraction was overestimated in dusty conditions and underestimated for smoke and pollution aerosol). As a result, MODIS AE has no significant bias as a whole but shows reduced contrast in space or time compared to AERONET. There is also a negative bias for large wind speeds. Balancing of errors in AE (see Eq. 1) is possibly the reason that $\mathrm{AE}$ bias hardly depends on AOT, cloud fraction or any other parameter. The random AE error depends strongly on AOT.

Finally, we point out that the variation of the discussed parameters is not completely independent. For example, there is a weak correlation between cloud fraction and wind speed, maybe because whitecaps are sometimes interpreted as cloudiness.

\subsection{Comparison against Maritime Aerosol Network}

MAN data has a substantially different spatial sampling than AERONET. Not only does MAN contain many observations over the deep ocean, but is also better balanced as regards the latitudinal distribution of observations (the majority of AERONET observations are made in the Northern Hemisphere). Here we will show that MODIS Terra AOT has very similar biases versus MAN as against the regular AERONET data, provided independent sub-samples of the full datasets are used (Sect. 3.4).

Figure 6 shows Terra error statistics for either AERONET or MAN using either the full datasets or independent subsamples. When using the full datasets (left column), MAN data suggest MODIS Terra AOT biases are at least 0.01 to 0.02 lower than AERONET data suggest. Note also that MODIS biases against MAN have a very different dependence on AOT than MODIS biases against AERONET. For independent sub-samples (right column), however, there clearly is a large similarity between the AERONET and 

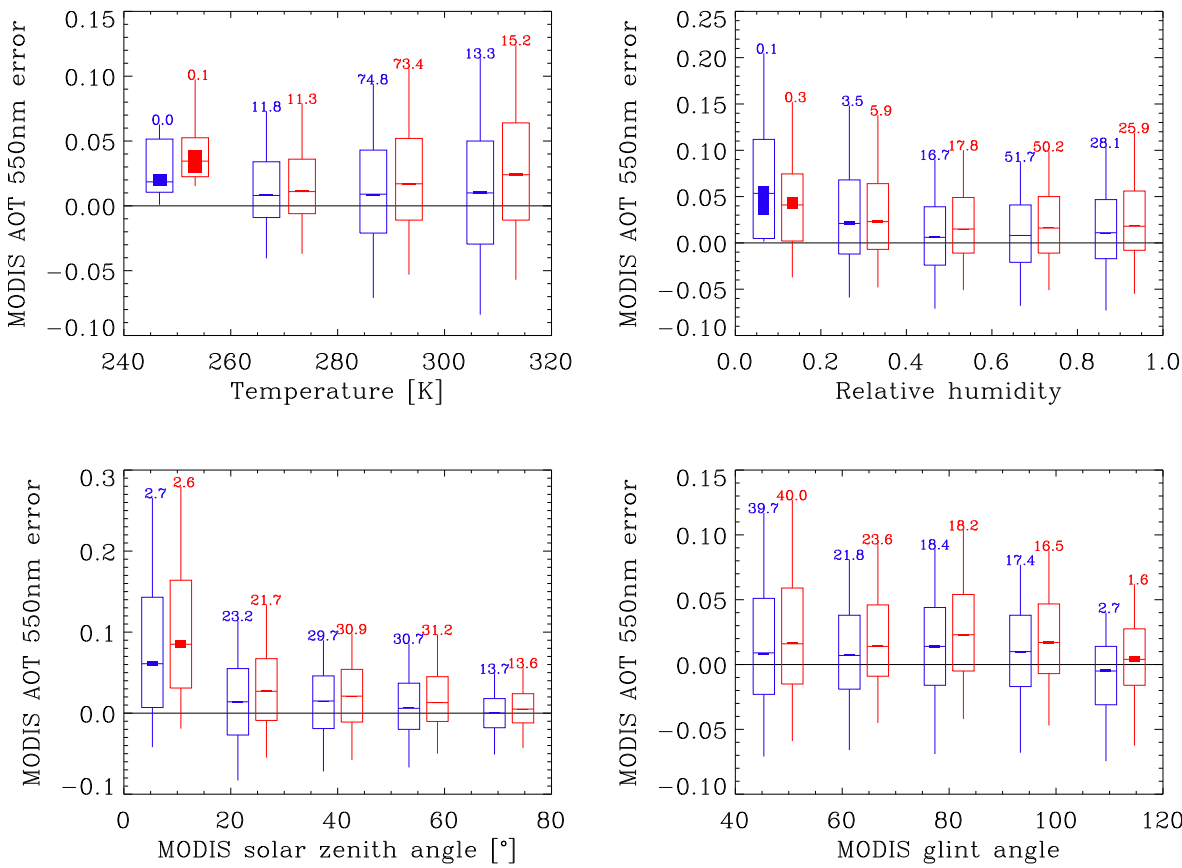

Fig. 4. MODIS AOT error statistics as a function of NCEP-DOE-II temperature $(2 \mathrm{~m})$ or relative humidity $(2 \mathrm{~m})$, MODIS scattering or glint angle (blue: Aqua; red: Terra). The box-whisker plots are offset from these bin centres to show the two distributions side by side. Numbers above the box and whisker show the percentage of the total sample used in that bin.
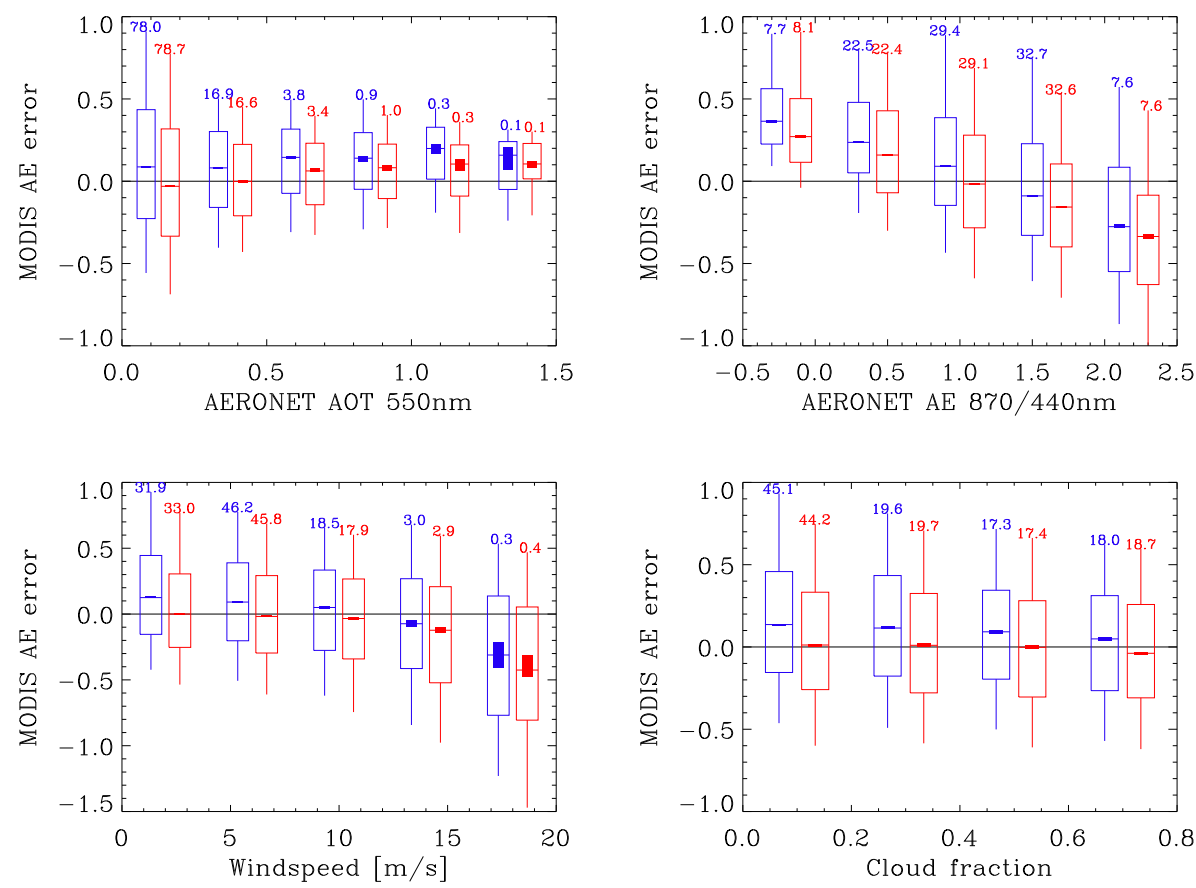

Fig. 5. MODIS AE error statistics as a function of AERONET AOT, AERONET AE, NCEP-DOE-II wind speed and MODIS cloud fraction (blue: Aqua; red: Terra). The box-whisker plots are offset from these bin centres to show the two distributions side by side. Numbers above the box and whisker show the percentage of the total sample used in that bin. 

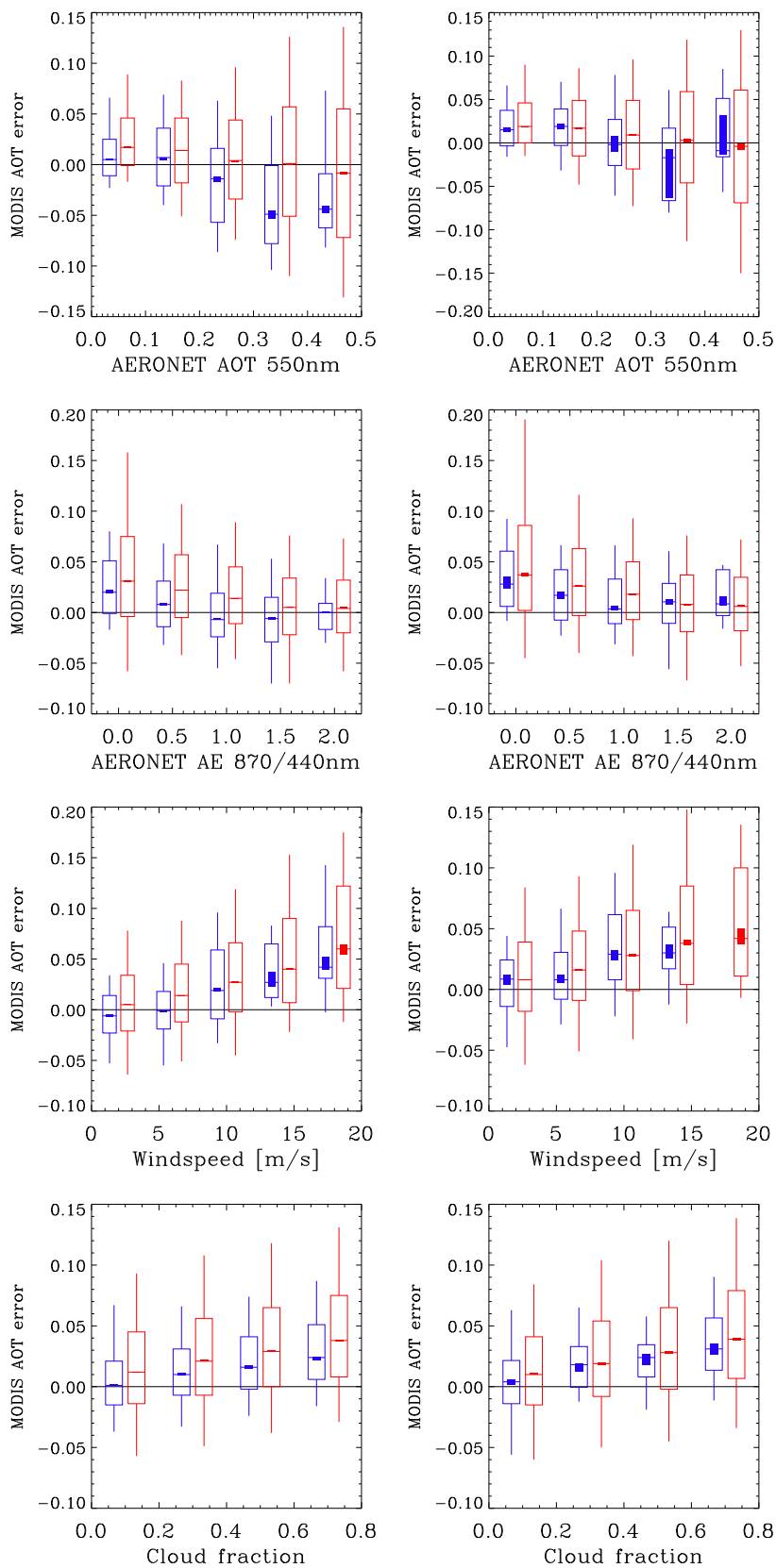

Fig. 6. Terra AOT error statistics against the Maritime Aerosol Network (blue) or AERONET for either the full dataset (left column) or independent sub-samples (right column). When using independent sub-samples, Maritime Aerosol Network and AERONET data yield very similar MODIS biases.

MAN comparison. Thus, comparison of MODIS against either AERONET or MAN yields similar biases provided independent sub-samples are used. The consequences are twofold: (1) it suggests that AERONET can be used for a globally representative MODIS error analysis; and (2) it suggests the importance of the independent sub-samples.

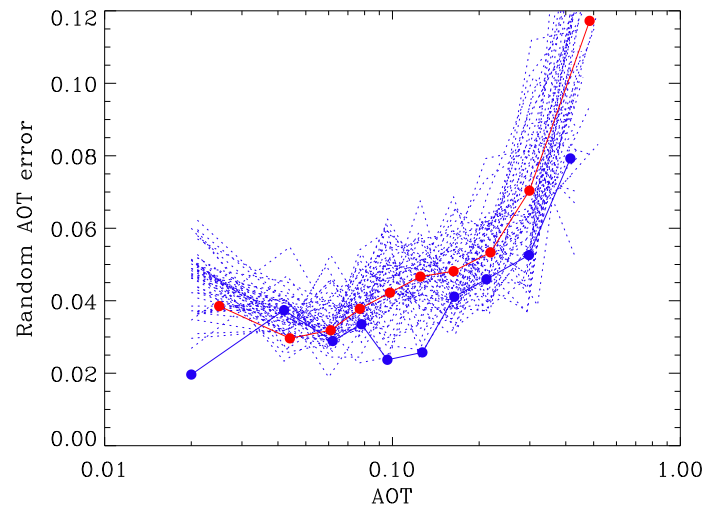

Fig. 7. Terra random AOT errors estimated from the Maritime Aerosol Network (solid blue) or AERONET (solid red). The blue dotted lines are MODIS random error estimates from AERONET data sampled to mimic Maritime Aerosol Network observing conditions.

Note that the independent sub-samples of MAN observations have a small size: only 395 (Aqua) or 426 (Terra) data pairs are available. Similar results can be shown for AE biases in MODIS Terra although the picture is noisier (the dataset is even smaller: 283). The comparison with Aqua yields ambiguous results. In particular, the bias in MODIS Aqua AOT vs. MAN shows no dependency on either AE or cloud fraction. Since this dependency has been shown to exist for MODIS Aqua against AERONET (see Zhang and Reid, 2006; Shi et al., 2011 and Sect. 4) and MODIS Terra against MAN, this is a surprising result. What is causing this remarkable deviation from a clear pattern is far from obvious to us.

Figure 6 seems to suggest there are differences in the random MODIS errors when using either AERONET or MAN data. However, MAN tends to observe lower values for AOT and AE than AERONET. We will later (Sect. 7) show that random MODIS errors depend strongly on AOT. In particular, AERONET's median AOT is 0.119 while MAN's median AOT is $0.077,30 \%$ lower. To make a meaningful comparison, Fig. 7 shows MODIS Terra random AOT errors estimated from either AERONET or MAN data as a function of AOT. It would appear the random errors estimated from AERONET data are somewhat larger than those estimated from MAN. However, if we sub-sample the AERONET data to a dataset that is close to MAN in terms of size, observed AOT, AE, wind speed and cloud fraction it turns out there is quite some variation in the estimated random error (dotted blue lines in the figure). Thus AERONET and MAN seem to suggest similar random MODIS errors, if differences in the sampling of the datasets are taken into account. Note that the MAN analysis has its own statistical uncertainty which is however difficult to assess due to its low sample size. 


\section{Empirical correction of MODIS AOT and AE}

In this section, we will describe a new method for empirically correcting MODIS observations through regression onto the co-located AERONET observations. Before doing this, we will further screen MODIS data by removing all MODIS observations for $T<260 \mathrm{~K}, \mathrm{RH}<0.2$ or SZA $<20^{\circ}$. The previous section showed that MODIS AOT biases were unusually large for those parameter values. This leads to a further reduction of about $3 \%$ in the sample size of our co-located observations.

\subsection{Screening of AERONET sites}

So far we have not really considered how appropriate the AERONET sites are for validation of MODIS observations. In the previous section we saw that AERONET sites at altitudes above $300 \mathrm{~m}$ generally show poorer agreement with MODIS data and this is likely due to the different air columns observed. Local emission sources or orography can similarly cause AERONET observations to not be representative of the larger area sampled by MODIS . By studying the correlation between MODIS and AERONET AOT per site we will try to remove unrepresentative AERONET sites. Thus we calculate correlation coefficients and linear regression coefficients for the co-located MODIS and AERONET data per site. If the number of co-located data per site is below 11 we discard that particular site from our analysis. If the correlation coefficient is below 0.5 or the regression coefficient below 0.5 or above 2.0 we also discard that site, because seemingly these AERONET observations are not representative of the co-located MODIS observations. The total loss in co-located data is $\sim 4 \%$, with most due to the minimum requirement for the number of observations. The number of discarded sites depends to some extent on the sensor and the chosen subsample, so this selection may be too conservative (i.e. remove even good data). The purpose of this screening is, however, to remove potentially unrepresentative sites, and it does no harm to err on the side of prudence. We have performed a sensitivity study where the criterium for the correlation coefficient was increased to 0.75 (this causes a $\sim 20 \%$ reduction in available data) with no major impact on the analysis presented in the following sections.

Sites that are consistently removed, independent of sensor or sub-sample, are Adelaide site 7, CEILAP-RG, Coconut Island, Crozet Island and St-Denis, Reunion. These sites all have sufficient number of observations co-located with MODIS, even after our screening, but show poor correlation with MODIS (MODIS AOT's are sufficiently high that we can ignore a signal-to-noise issue). We contacted their respective PI's, hoping to understand why there might be a big discrepancy between MODIS and those sites. Unfortunately, no obvious reasons could be found. Note that we include in our analysis several sites that Ichoku et al. (2005b) excluded.

\subsection{Methodology of the empirical correction}

A correction of MODIS AOT and AE is now developed as a regression of the MODIS bias unto the predictors of this bias: AOT, AE, wind speed and cloud fraction. A correct regression faces several obstacles: the non-Gaussian distribution of the observations (in particular, the strongly skewed distribution of AOT itself and the many outliers in the MODIS errors), the multiple parameters that influence the MODIS observations (sometimes non-linearly, see previous sub-section) as well as the (weak) interdependency of some of these parameters. As robust non-linear multiple regression is a field very much in development and no standard techniques are yet available, we decided to pursue a common sense approach.

Looking at Fig. 3, it appears rather straightforward to develop corrections for the AOT bias due to wind speed and cloud fraction. For instance, the wind speed correction could be based on a linear regression of the bias unto wind speed. Similarly, a cloud fraction correction may be developed. If these corrections are developed independently, the combination of both corrections may actually yield a product that is less accurate than the standard product. Instead, one could first develop a correction for wind speed and then correct the wind-speed corrected MODIS AOT for cloud fraction. Or the other way around: first correct for cloud fraction and then for wind speed. This does not automatically lead to an improved product, but there are now two correction algorithms that are different and hopefully at least one leads to MODIS AOT with significantly reduced biases overall.

In practice, we want to correct not only for wind speed and cloud fraction, but also AOT and AE. As AERONET AOT and $\mathrm{AE}$ are not available for the majority of MODIS observations, we will use their MODIS observed counterparts as proxies. As a possible MODIS correction algorithm, we now define any particular permutation of sequential correction by AOT, AE, wind speed and cloud fraction ( $4 !=24$ algorithm). The corrections due to AE, wind speed and cloud fraction can either be added to or multiplied with the MODIS AOT $\left(2^{3} \times 24=192\right.$ algorithms $)$. Finally, the AOT bias as a function of AOT seems to exhibit two regimes: constant for small AOT and a linear dependence for larger AOT (not shown). We therefor develop separate correction algorithms for low and for high AOT. Furthermore, we will optimize the threshold AOT value that distinguishes the regimes by attempting 5 different values (Zhang and Reid, 2006, and Shi et al., 2011, assumed a threshold of 0.2). All in all, we developed 960 different algorithms per AOT regime.

The actual regression of the MODIS bias unto a single parameter, say cloud fraction, is performed as follows: first we divide the cloud-fraction data in 4 bins with equal number of observations. For each bin, a median cloud fraction, median MODIS error (i.e. the bias for that bin) and an error estimate in the later are determined. The linear regression through these values constitutes one particular correction formula. 

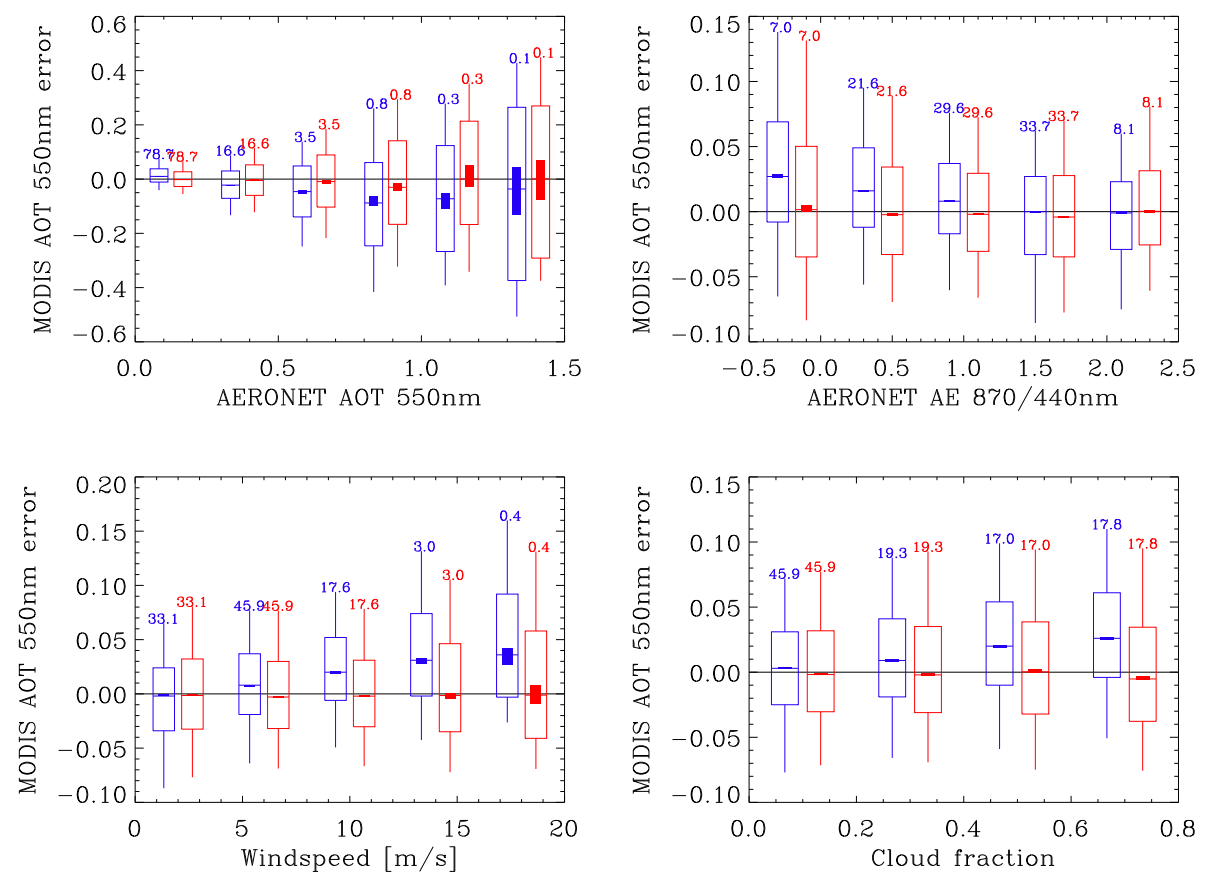

Fig. 8. MODIS Aqua AOT error statistics as a function of AERONET AOT, AERONET AE, NCEP-DOE-II wind speed and MODIS cloud fraction for the original (blue) and the corrected AOT (red). The box-whisker plots are offset from these bin centres to show the two distributions side by side. Numbers above the box and whisker show the percentage of the total sample used in that bin.

The optimal algorithm is a sequence of correction formulae that minimize the MODIS bias the most. Since there is a substantial contribution from random errors in the MODIS data, a special metric was used to assess that reduction. We will call this metric the fitted bias and it is determined as follows. First, we divide the MODIS data (after application of a correction algorithm) in four bins with equal number of AOT (or AE) observations. For each AOT bin separate regressions of MODIS error vs. AOT, AE, wind speed or cloud fraction are made. As an indication of the bias resulting from e.g. wind speed, we will use the $\mathrm{RMS}^{6}$ value of the regression against e.g. wind speed in each AOT bin. These RMS values can be averaged over all AOT bins and all four parameters $\mathrm{AOT}, \mathrm{AE}$, wind speed and cloud fraction to yield a single representative value, called fitted bias. Note that this is a very different value from e.g. the RMS difference of MODIS and AERONET AOT, as the latter will be dominated by substantial random errors. The fitted bias will be used to compare algorithms. In practice, various algorithms will perform similarly good or bad and it is not possible to single out any algorithm as the optimal algorithm. This is not necessary anyway. What is important is that there are algorithms that substantially reduce the fitted bias, while others fail and may even increase it.
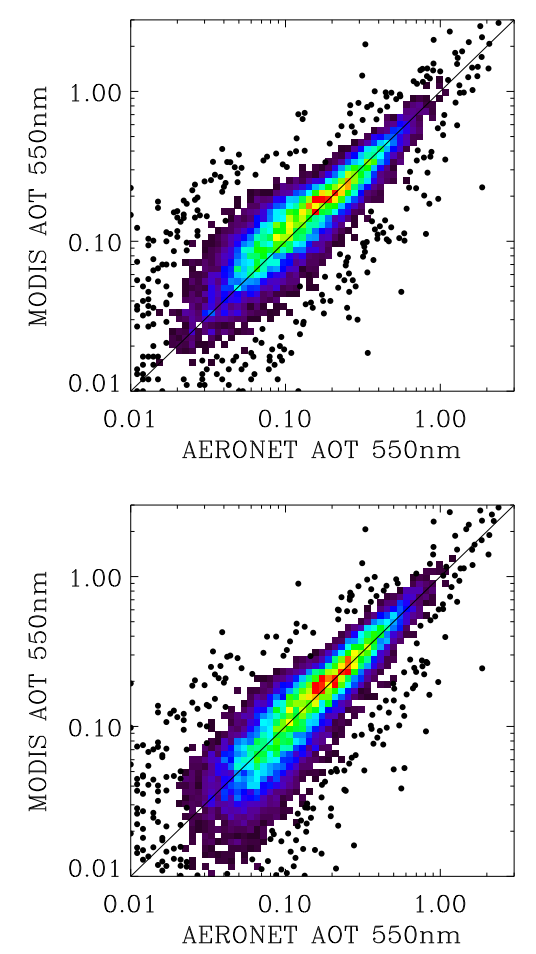

Fig. 9. Density plots of MODIS Aqua AOT vs. AERONET AOT for the original (top) and corrected (bottom) observations.

${ }^{6} \mathrm{RMS}$ : root mean square. 

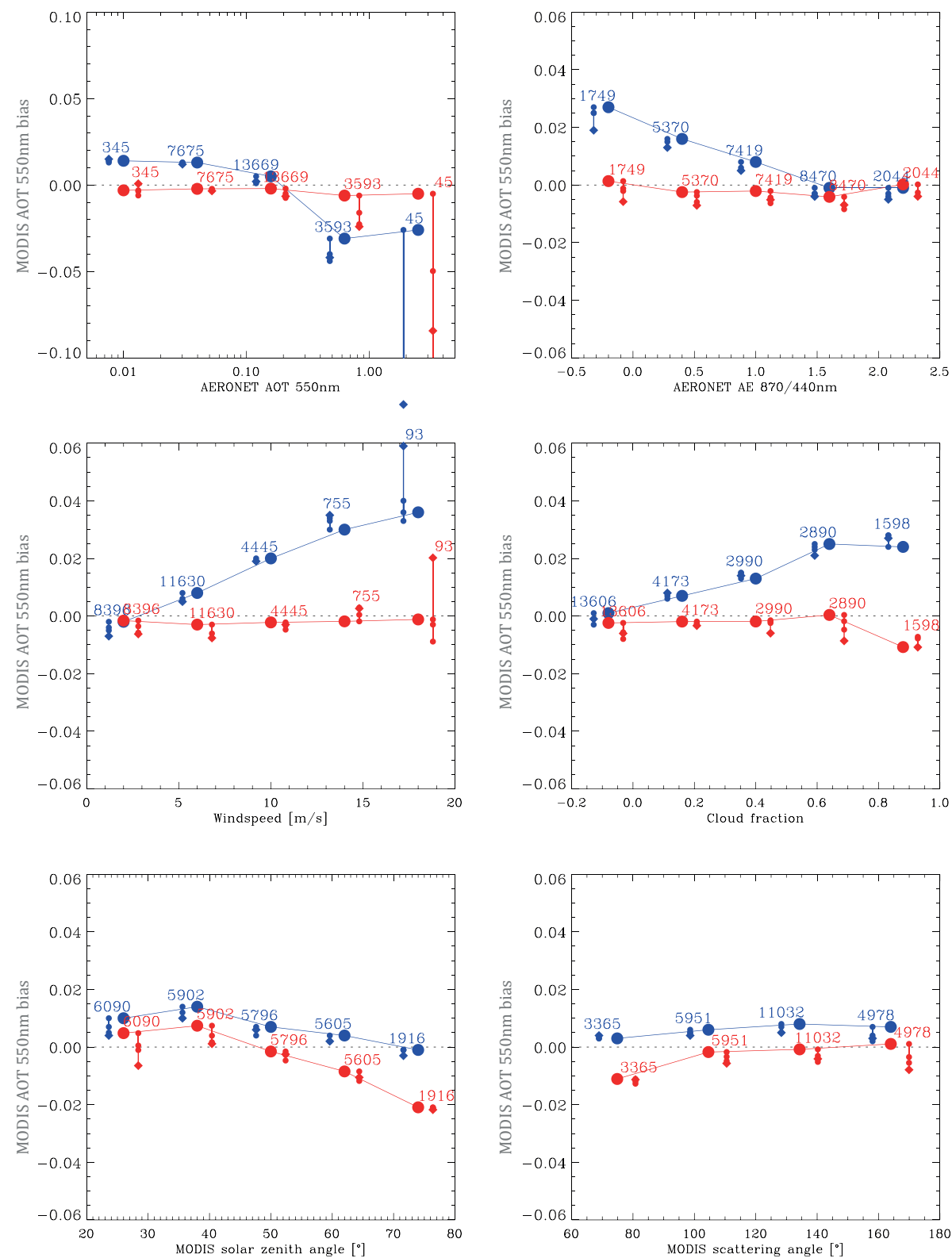

Fig. 10. Biases in Aqua AOT as a function of several variables, for both the original (blue) and corrected (red) observations. The numbers in the plot show sample size per bin. The fatter dots, connected by lines, show the biases for the sub-sample that was used to construct the correction algorithm (closest). The dots along the vertical bars represent the biases for three sub-samples (closest, random or farthest). The diamond represents the bias for the full dataset.

\subsection{Results for MODIS AOT}

We can reduce the fitted bias for AOT by a factor of $\sim 3$. In the case of Terra, it is useful to also include a correction based on scattering angle. The optimal correction algorithms are presented in Appendix A.

For Aqua, the fitted bias is reduced from 0.018 to 0.007 . Figure 8 shows how the biases change as a function of AOT, AE, wind speed and cloud fraction. Clearly, Aqua random errors hardly change (respectively 0.076 and 0.077 ).
Correlation coefficients for all MODIS-AERONET AOT pairs also barely change, from 0.86 to 0.87 , but the coefficient of a robust linear regression experiences a significant increase (from 0.89 to 0.99 ). A density plot (Fig. 9) of Aqua AOT vs. AERONET AOT shows a striking improvement in the agreement with AERONET at low AOT. We also see an improvement of MODIS AOT per AERONET site. For example, the median of the distribution of linear regression coefficients per AERONET site changes from 0.90 to 1.00. Due to the correction, the median value of Aqua AOT changes 


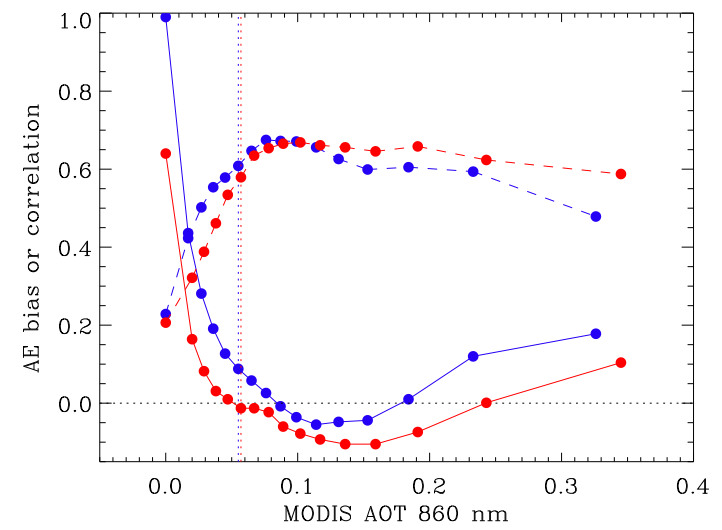

Fig. 11. Bias and correlation of MODIS AE vs. AERONET AE for Aqua (blue) and Terra (red). Bias and correlation were calculated for MODIS AOT at $860 \mathrm{~nm}$ bins. The horizontal axis shows the lower AOT value of each bin. Bins contain equal numbers of observations (per bin $6.25 \%$ of all observations). The vertical lines are the chosen thresholds.

by -0.013 , with $25 \%$ of the data experiencing a reduction of more than $29 \%$.

For Terra, the fitted bias is reduced from 0.018 to 0.006 . Neither the Terra random error (from 0.078 to 0.079 ) nor the correlation hardly change (from 0.87 to 0.89 ). A robust linear regression over all MODIS-AERONET data pairs sees a small increase in the coefficient (from 0.95 to 1.00). The median of the regression coefficients per AERONET site changes from 0.97 to 1.01 . In the case of Terra, the median value of AOT changes by -0.022 , with $25 \%$ of the data experiencing a reduction of more than $36 \%$ due to this correction.

The correction algorithm seems robust. In Fig. 10, we show remaining biases in Aqua observations when the correction algorithm from Appendix A is applied to different independent sub-samples (e.g. farthest co-located pixel) as the sub-sample for which it was developed (closest co-located pixel). Although there is scatter, the results for the independent sub-samples tend to cluster, while the results for the full dataset are sometimes rather different. In particular, there is a big difference for high wind speeds.

For Terra, similar results can be shown.

As a last independent test, we applied the correction algorithm to data for 2011 and 2012. The inspection of graphics, as shown in this section, shows that also for this time period the correction formula works well. Since there is less data, results are noisier but overall the fitted bias is reduced (from 0.028 to 0.009 ) and the regression coefficient is slightly improved ( 0.87 to 0.87$)$ for Terra AOT. For Aqua, the fitted bias remains the same $(0.018$ and 0.017$)$ for and the regression coefficient increases from 0.76 to 0.84 . Sample sizes are less than 2000.

\subsection{Results for MODIS AE}

Before we discuss the correction of MODIS AE, we will study MODIS AE derived from Eq. (1) further. Errors in AE are determined by errors in AOT, so we wonder how well MODIS and AERONET AE agree depending on MODIS AOT. Because AOT tends to decrease with wavelength, we assume that the impact of erroneous surface albedo (due to whitecaps or cloudiness) on AOT retrievals will be more felt at, e.g. $860 \mathrm{~nm}$ than at $470 \mathrm{~nm}$. Certainly, relative random MODIS errors at $860 \mathrm{~nm}$ appear to be $20 \%$ larger than at $470 \mathrm{~nm}$. In Fig. 11, we show the correlation and bias of MODIS AE with respect to AERONET AE as a function of MODIS AOT at $860 \mathrm{~nm}$. For low AOT at $860 \mathrm{~nm}$, correlations are small and biases are large which suggests it would be difficult to develop correction algorithms. When one inspects scatter plots for individual AOT bins, one sees that for low AOT, MODIS often has $\mathrm{AE}>2$. In particular there appears to be a peak in the $\mathrm{AE}$ histogram for $\mathrm{AE} \sim 2.7$. We therefor choose minimum thresholds $\left(\tau_{860}>0.055\right)$ for MODIS $\tau_{860}$ before we continue our analysis (resulting in a loss of $31 \%$ of AE data).

The correction of $\mathrm{AE}$ proceeds in the same way as that of AOT. We can reduce the fitted bias for AE by a factor of 2 . The correction includes influences from $\mathrm{AE}$, wind speed and scattering angle. The optimal correction algorithms are presented in Appendix A.

For Aqua AE, the fitted bias is reduced from 0.09 to 0.046 , but the RMS component due to $\mathrm{AE}$ is reduced from 0.24 to 0.07 . Figure 12 shows how the biases change as a function of AOT, AE, wind speed and cloud fraction. As a consequence of the bias correction, random errors increase from 0.40 to 0.54 (a consequence of the rescaling of $\mathrm{AE}$ ). The correlation coefficient between MODIS and AERONET $\mathrm{AE}$ does not change (0.69) but the linear regression coefficient changes significantly from 0.58 to 0.94 . A density plot (Fig. 13) of Aqua AE vs. AERONET AE shows a striking improvement in the agreement with AERONET. The median of regression coefficient per AERONET site changes from 0.53 to 0.86 .

For Terra AE, the fitted bias is reduced from 0.12 to 0.07 while the RMS component due to AE is reduced from 0.24 to 0.11 . As a consequence of the bias correction, random errors increase from 0.41 to 0.51 . Again, the correlation coefficient does not change $(0.69)$ but the robust linear regression coefficient changes from 0.63 to 0.94 . The median of the regression coefficients per station changes from 0.58 to 0.83 .

As was the case for AOT biases, the AE correction scheme seems robust. In Fig. 14, we show remaining biases in Aqua observations when the correction algorithm from Appendix A is applied to different sub-samples (e.g. farthest colocated pixel) as the sub-sample for which it was developed (closest co-located pixel). Although there is scatter, the results for the independent sub-samples tend to cluster, results for the full dataset are not much different. 

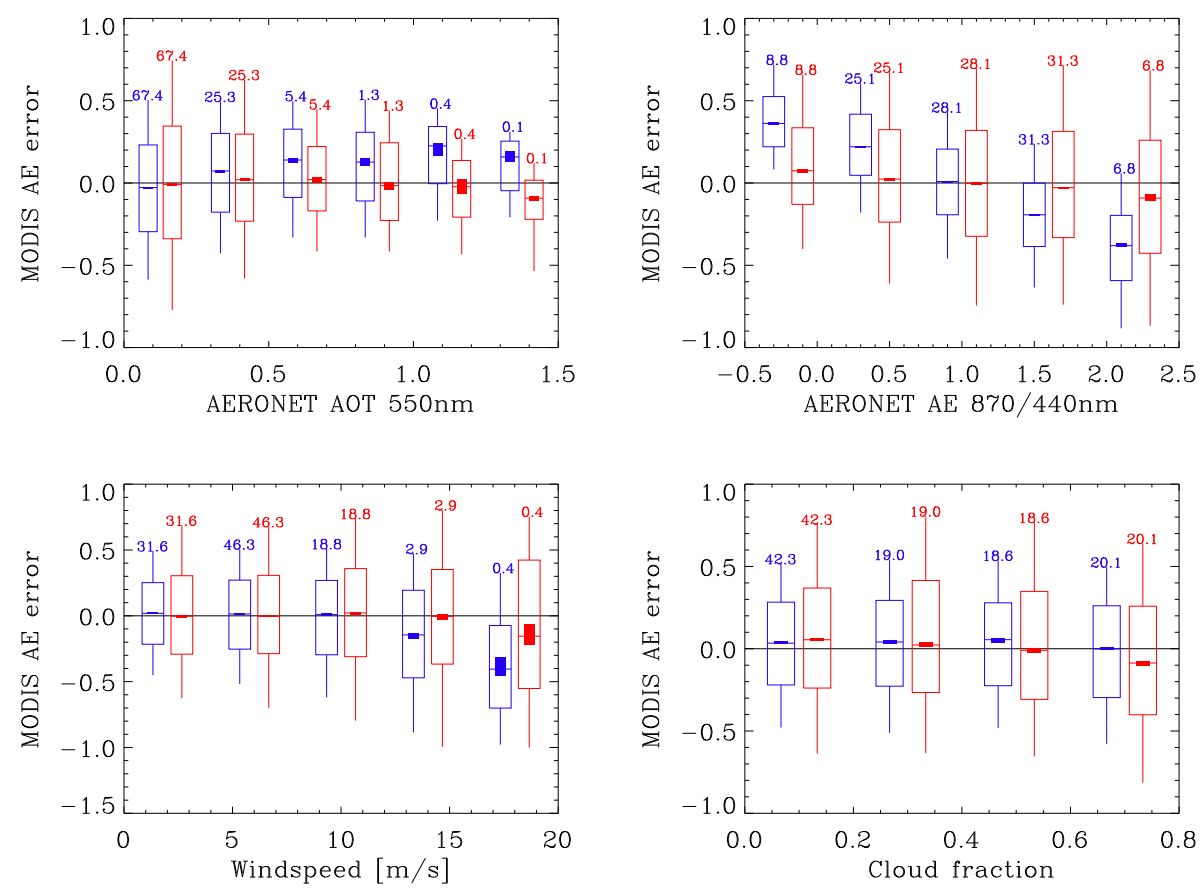

Fig. 12. MODIS Aqua error statistics as a function of AERONET AOT, AERONET AE, NCEP-DOE-II wind speed and MODIS cloud fraction for the original (blue) and the corrected AE (red). The box-whisker plots are offset from these bin centres to show the two distributions side by side. Numbers above the box and whisker show the percentage of the total sample used in that bin.
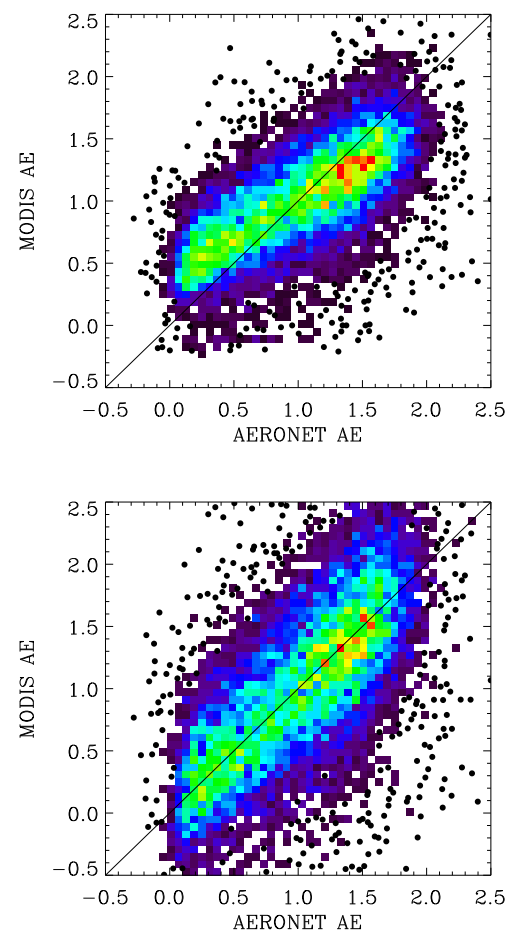

Fig. 13. Density plots of MODIS Aqua AE vs. AERONET AE for the original (top panel) and corrected (bottom panel) observations.
For Terra, similar results can be shown.

As a last independent test, we applied the correction algorithm to data for 2011 and 2012. The inspection of graphics, as shown in this section, shows that also for this time period the correction formula works well. Since there is less data, results are noisier but overall the fitted bias is reduced (from -0.1 to -0.02 ) and the regression coefficient is improved (0.55 to 0.75) for Terra AE. For Aqua, the fitted bias increases from -0.027 to 0.028 and the regression coefficient increases from 0.56 to 0.91. Sample sizes are less than 2000.

\section{Multi-year averages of MODIS AOT and AE}

In this section, we will show the impact of the corrections on the 2003-2009 averages of MODIS Aqua AOT and AE. We will show figures of the original MODIS Coll. 5 level 2 product, the screened product (Sect. 3) and the corrected product (Sect. 5). Only MODIS Aqua will be considered here, Terra shows very similar results. These multi-year averages should not be taken as climatologies, as we have not made any effort to homogenize spatial and temporal sampling. In particular, the original and the screened product differ simply because many observations are discarded. The screened and corrected product have, however, the same spatial and temporal sampling.

In Fig. 15 we show MODIS Aqua AOT. Both the screening and correction lead to substantial changes in AOT 

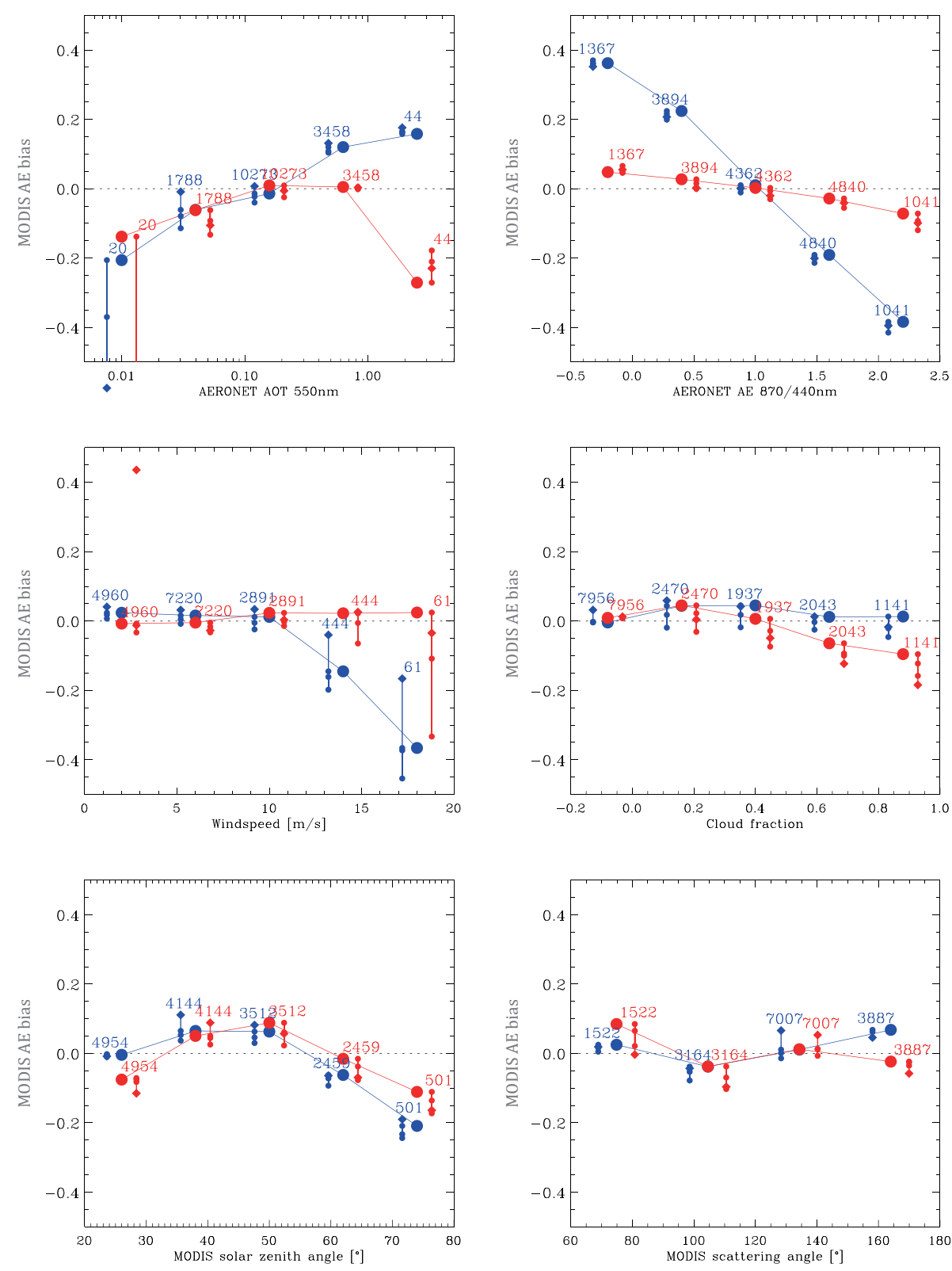

Fig. 14. Biases in Aqua $\mathrm{AE}$ as a function of several variables, for both the original (blue) and corrected (red) observations. The numbers in the plot show sample size per bin. The fatter dots, connected by lines, show the biases for the sub-sample that was used to construct the correction algorithm (closest). The dots along the vertical lines show the biases for three sub-samples (closest, random and farthest). The diamond represents the bias for the full dataset.

distribution. In particular, over cloudy regions many observations are discarded. The correction strongly reduces spatial variation in AOT. Note there is nothing in the correction algorithm that produces such a result a priori. Continental outflows extend less far across the oceans, and the elevated band of AOT at southern midlatitudes has mostly disappeared. It turns out that the corrections have different causes depending on the region. First, the large majority of uncorrected AOT are small and have only a small impact on the correction (e.g. Fig. 3). Secondly, the cloud fraction in the MODIS aerosol product does not show much spatial variation in a yearly average (note there is no reason for it to show typical climatological patterns as high levels of cloudiness pre-empt aerosol retrievals anyway) and is more or less an offset correction (about -0.01 in the yearly mean). The spatial variations in the corrections are then mainly due to (uncorrected) $\mathrm{AE}$ and wind speed, which have very pronounced spatial patterns. Wind speed has a distinctly latitudinal pattern with low speeds near the Equator and high speeds north of $30^{\circ} \mathrm{N}$ and between $40-60^{\circ} \mathrm{S}$, while the spatial pattern of uncorrected 


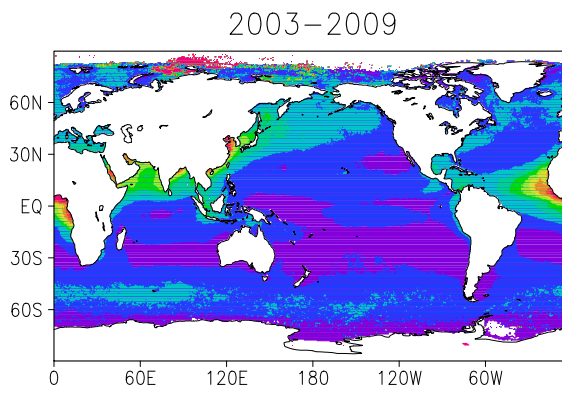

2003-2009

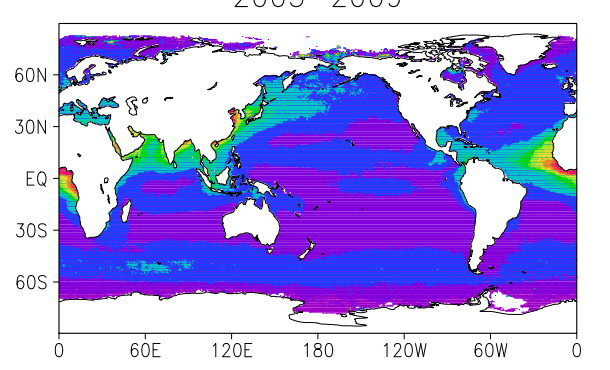

$2003-2009$

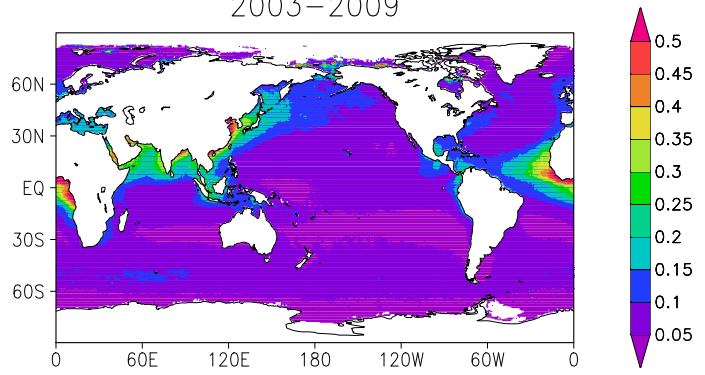

Fig. 15. Multi-year averages (2003-2009) of MODIS Aqua AOT. The top panel shows the original MODIS Coll. 5 level 2 product. The middle panel shows the screened product and the bottom panel shows the corrected product.

$\mathrm{AE}$ is shown in the middle panel in Fig. 16. Both can locally lead to corrections of about -0.02 in the yearly mean.

In Fig. 16 we show MODIS Aqua AE. Again, both the screening and the corrections lead to significant changes in $\mathrm{AE}$. The screening removes very high $\mathrm{AE}$ values at high latitudes, while the correction increases $\mathrm{AE}$ close to land and decreases it for the middle of the ocean. As a consequence, land-ocean and north-south gradients become more pronounced. Due to the correction, regional detail increases: there is more contrast between the dust and carbon outflows on the western coast of Africa, and between Indian (pollution) and Arabian (dust) outflows. The correction of AE is mainly due to uncorrected $\mathrm{AE}$, which tends to decrease low $\mathrm{AE}$ and increase high $\mathrm{AE}$.

\section{Random errors in MODIS AOT and AE}

In this section, we will address the random errors in the corrected MODIS AOT and AE. In Figs. 8 and 12 we indicated
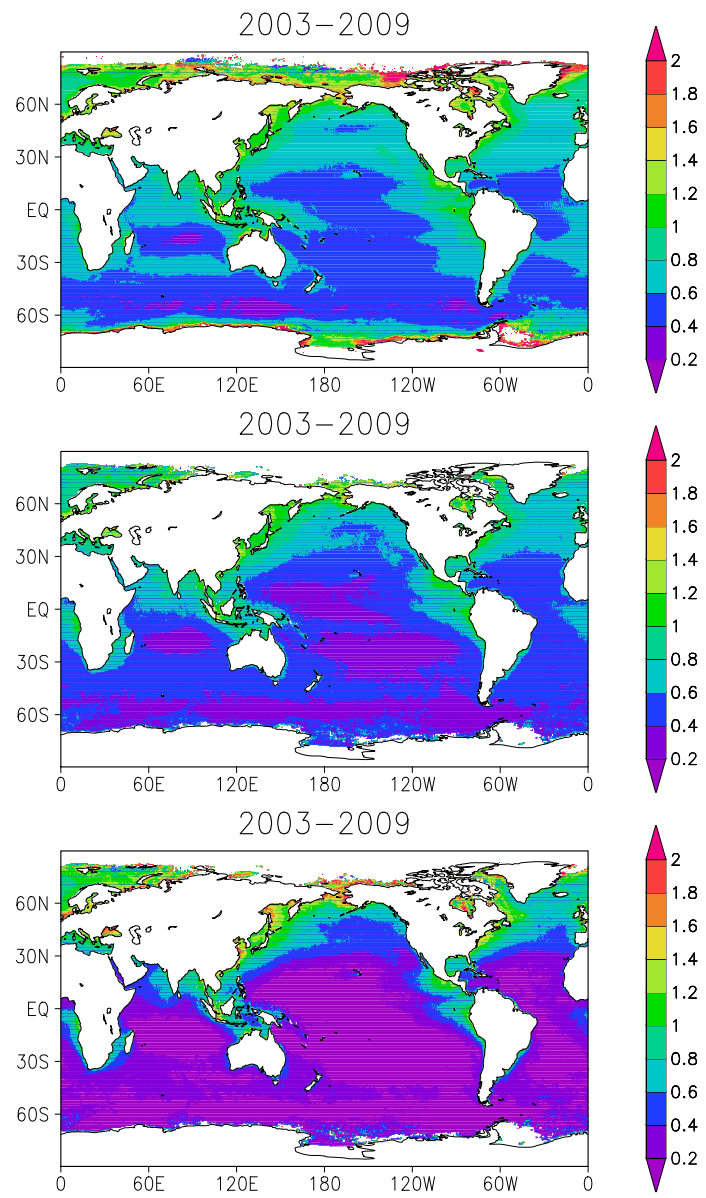

Fig. 16. Multi-year averages (2003-2009) of MODIS Aqua AE. The top panel shows the original MODIS Coll. 5 level 2 product. The middle panel shows the screened product and the bottom panel shows the corrected product.

this error as the interquantile range for various $\mathrm{AOT}, \mathrm{AE}$, wind speed and cloud fraction bins. Both the AOT and AE random error depend on AOT itself, but there appear to be dependencies on other parameters as well. This random error is usually expressed as the standard deviation of a distribution of errors, but we will use half the quantile range from 15.8 to $84.2 \%$. Since our error distributions generally have narrower peaks and wider wings than Gaussian distributions and may also be skewed, quantiles seem a more appropriate measure as the common standard deviation tends to overestimate the width of the distribution. In Fig. 17 we show actual Aqua AOT error distributions per AERONET AOT bin, as well as fitted distributions based on either the standard deviation or our proposed interquantile range. Especially for low and high AOT, a Gaussian distribution based on an interquantile range appears the better choice.

We now present simple models for the random errors based on the assumption that the various error sources are independent. These models were built in a trial and error 

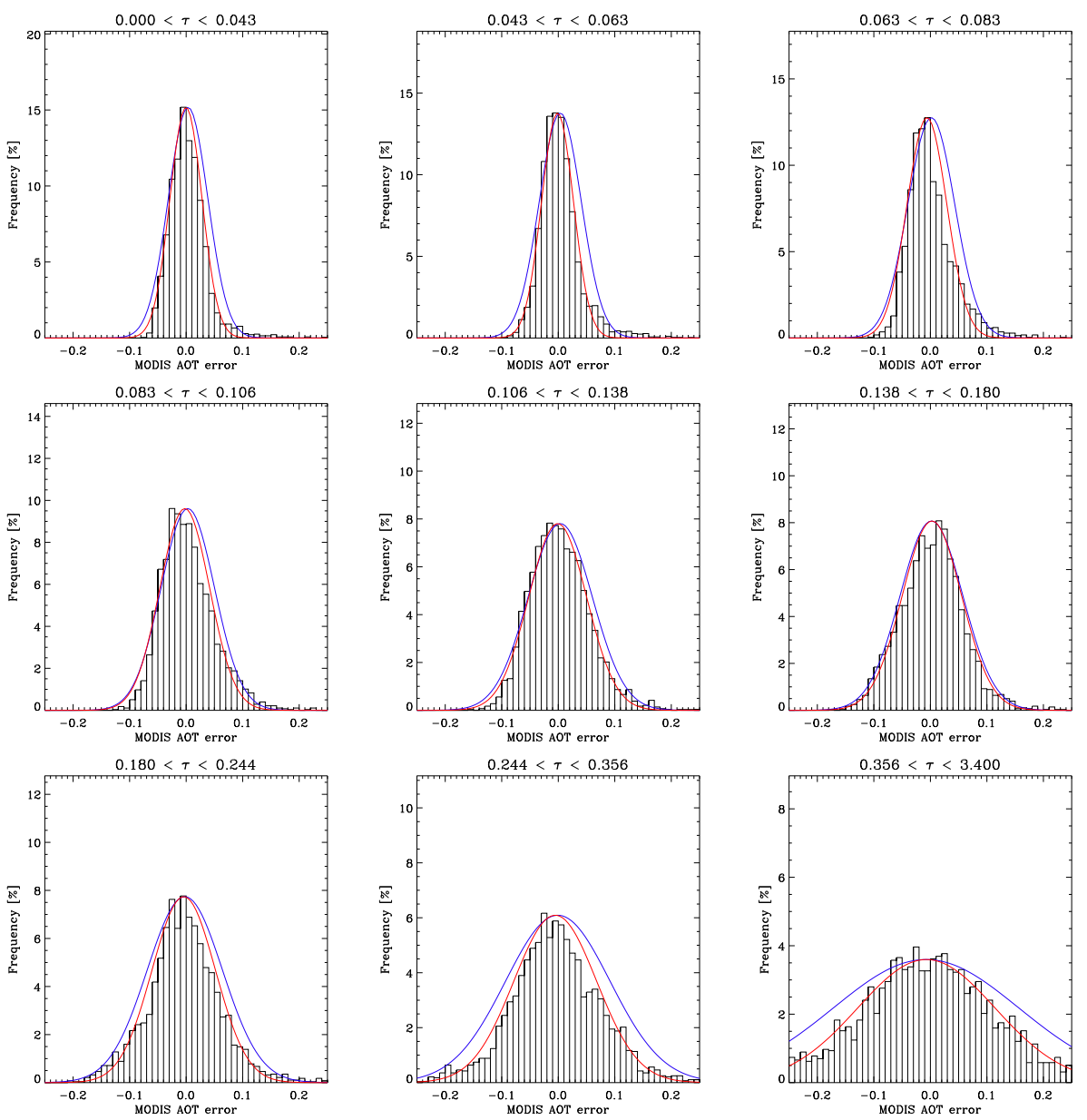

Fig. 17. Aqua AOT error distributions for the corrected observations as a function of AERONET AOT. Also shown are two Gaussian distributions that where fitted to the data, using two different methods for estimating the standard deviation. One method uses the actual standard deviation of the sample (blue), the other method uses the random error as defined in this paper (red). The random error leads to a better agreement with the actual distribution due to the presence of outliers.

manner. In the case of AOT random errors, for instance, we first considered only observations for low cloudiness and wind speed. For those observations, a function in AOT was sought that well described the random errors. Next, all observations were considered and small corrections due to wind speed and cloud fraction were added.

Figure 18 shows the random errors in AOT for Aqua as a function of binned AOT, AE, wind speed or cloud fraction. We also show the estimate from our simple model (see also Appendix A), which agrees quite nicely. Note that the apparent variation in AOT random error with $\mathrm{AE}$ results mostly from AOT variations (low AE often implies high AOT, which leads to higher random errors).

The random error in $\mathrm{AE}$ as a function of binned $\mathrm{AOT}, \mathrm{AE}$, wind speed or cloud fraction is shown in Fig. 19. Again, our simple error model agrees nicely. As expected, AOT has a huge impact on $\mathrm{AE}$ random error, but its variation with AE cannot be solely understood due to AOT sampling alone (i.e. AE influences the $\mathrm{AE}$ random error, with larger $\mathrm{AE}$ having a larger random error).

These random error models use AERONET AOT and AE as independent variables. Since we removed biases in the MODIS data, it is also possible to use corrected MODIS AOT and $\mathrm{AE}$ as independent variables. We preferred to derive the error models for AERONET values, as it turned out difficult to fit an error model using MODIS values (likely due to the significant random errors in the independent variable).

Finally, we compare the above random error models with those found in previous papers. We will limit ourselves to the AOT dependency only. The top panel of Fig. 20 show random AOT errors. The estimate by Remer et al. (2005) is clearly lower than estimates by Zhang and Reid (2006), Shi et al. (2011) and this study. The latter studies agree in a general way but we find larger errors for large AOT. The bottom panel of the same figure shows $\mathrm{AE}$ random errors. The dashed lines show AE errors predicted from AOT errors. In 

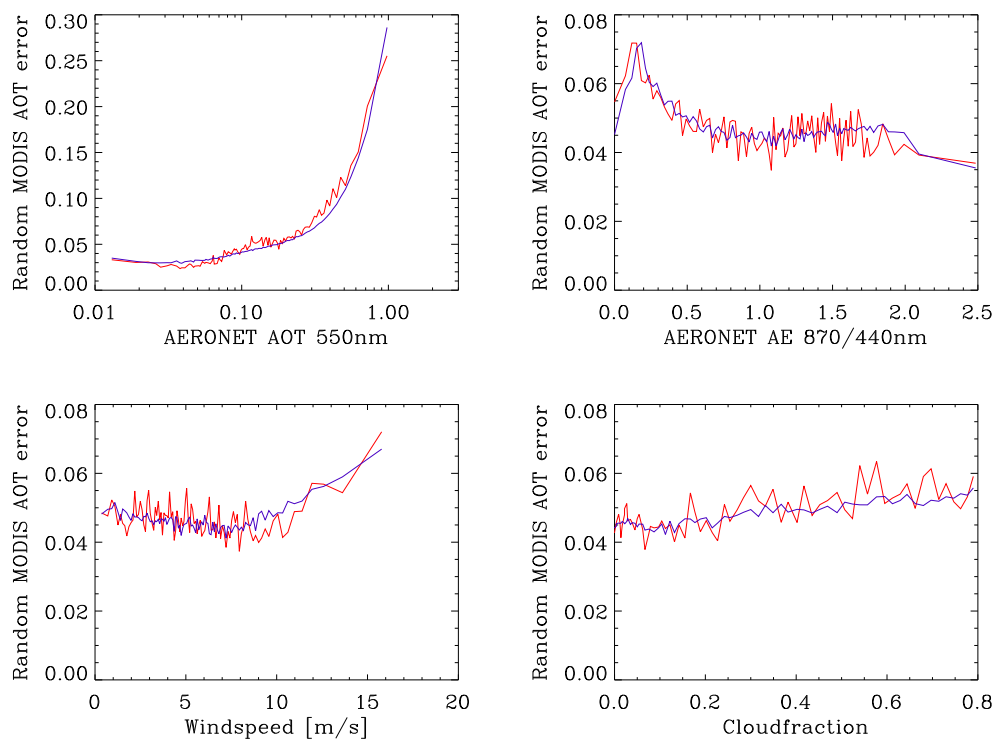

Fig. 18. Random Aqua AOT errors in the corrected observations. In red, the error estimated from binned observations, in blue our error model.
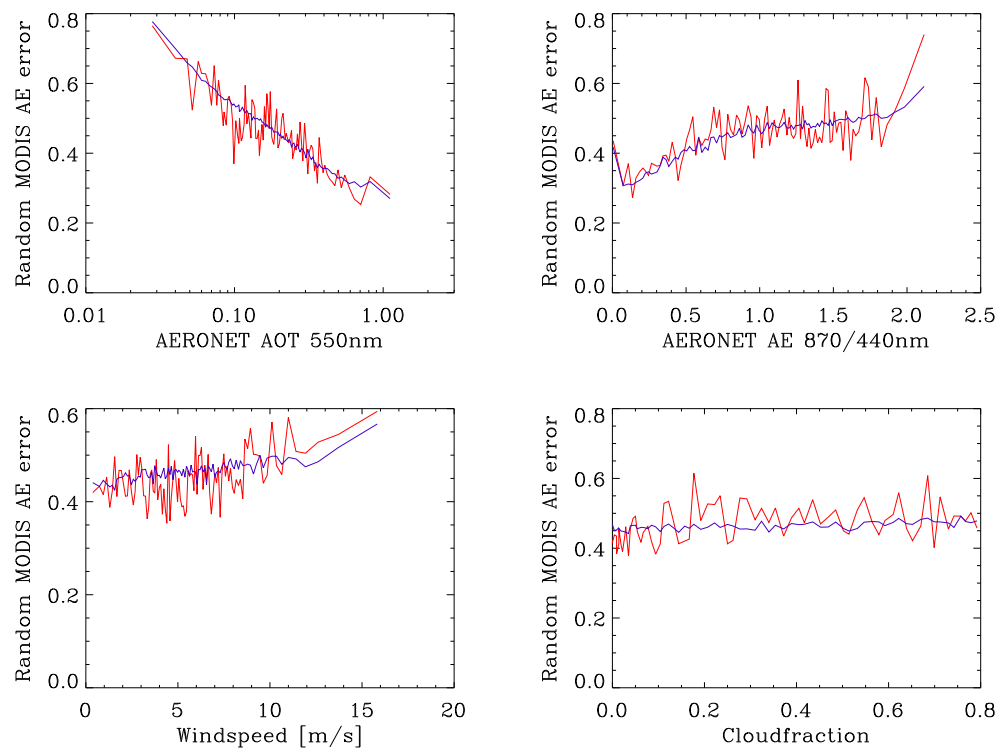

Fig. 19. Random Aqua AE errors in the corrected observations. In red, the error estimated from binned observations, in blue our error model.

that prediction we assumed identical but uncorrelated errors at the two wavelengths, in which case (see also Eq. 1)

$\Delta \alpha=\frac{\sqrt{1 / \tau_{1}^{2}+1 / \tau_{2}^{2}}}{\log \lambda_{2} / \lambda_{1}} \Delta \tau$

As the actual random AE errors (solid line) are often lower (even lower than AE errors estimated from Remer et al. (2005) AOT errors), it would appear that substantial correlations in AOT errors at different wavelengths (that are obvious in our dataset) reduce $\mathrm{AE}$ random errors, just as we hoped (see Sect. 1).

\section{Conclusions}

We have validated Coll. 5 MODIS level 2 AOT and AE observations over ocean against collocated AERONET and MAN observations. Based on this study, we propose additional quality control selection criteria and empirical correction algorithms to construct a smaller subset of MODIS observations that agree optimally with AERONET. This subset has similar spatial and temporal coverage as the full MODIS dataset but greatly reduced biases. Random errors of the corrected observations are also evaluated and error models developed. Random AOT errors for $\tau>0.1$ are shown to 

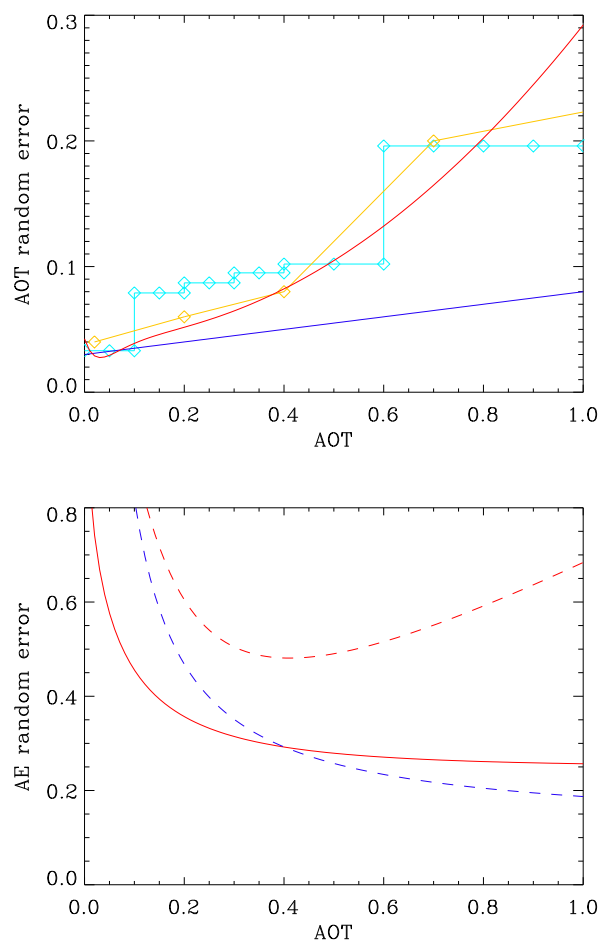

Fig. 20. Comparison of random error estimates for MODIS Aqua AOT and AE. In the top panel, AOT random errors estimated by Remer et al. (2005) (blue), Zhang and Reid (2006) (light blue), Shi et al. (2011) (orange) and this study (red). In the bottom panel, AE random errors estimated in this study (solid red). Also shown are errors predicted from Eq. (3) and AOT random errors estimated either by Remer et al. (2005) (dashed blue) or this study (dashed red).

be larger than the error estimate often used $(0.03+0.05 \tau)$. Random AE errors are shown to be smaller than might be expected.

Our work is both an extension and a variation of work done by Zhang and Reid (2006) and Shi et al. (2011). The extension consists of an analysis of MODIS AE observations over ocean and greater detail in the behaviour of MODIS biases and random errors as well as corroborative evidence from the Maritime Aerosol Network. The variation is in a different statistical approach (using independent sub-samples) and a different construction of the correction algorithm (that allows optimization of not only its parameters but also its structural form). We also use a different reanalysis dataset (NCEPDOE-II) to obtain auxiliary data such as wind speeds.

Our study suggests that the choice of using either the full dataset or an independent sub-sample has an impact on MODIS biases. In particular, we note a larger (positive) AOT bias for high AOT $(>0.5)$ and a lower (positive) AOT bias for high wind speeds $\left(>16 \mathrm{~m} \mathrm{~s}^{-1}\right)$ when using an independent sub-sample. Optimization of the structural form of the bias correction obtains a threshold AOT value (that separates low and high AOT regimes with different correction algorithms) that is quite different $(\sim 0.05)$ from the value of 0.2 used in Zhang and Reid (2006) and Shi et al. (2011). Finally, the use of quantiles as error metrics may explain why we can treat random errors with a Gaussian distribution and do not suffer (too much) from skewed error distributions.

Like Zhang and Reid (2006), Shi et al. (2011) and other authors we note the increase in MODIS AOT bias with increasing wind speed or cloud fraction. This is probably due to incorrect assumptions for the surface albedo. We note that in Coll. 6 steps have been taken to represent more different sea states.

We show that there is a useful signal in MODIS AE, after proper screening (including a minimum value threshold on associated $\left.\tau_{860}\right)$. AE serves a similar role as fine mode fraction (separation of coarse and fine mode aerosol), but has several advantages as detailed in this paper (see Sect. 1). We provide a full error analysis (bias and random errors) for MODIS $\mathrm{AE}$ and show that MODIS AE biases depend mostly on AE itself, suggesting issues with the aerosol scattering models used in the retrieval (this is also suggested by a random error in AOT that increases with AOT). To our knowledge, this is the first paper that discusses a correction to MODIS AE biases.

As a result of our corrections, MODIS AOT reduces by at least $30 \%$ for $25 \%$ of the observations and the elevated AOT over the Southern Ocean have mostly disappeared. MODIS $\mathrm{AE}$ decreases by at least 0.2 for $25 \%$ of the observations and increases by at least 0.2 for another $25 \%$ of the observations, leading to increased AE contrasts between the Northern and Southern Hemispheres and between coastal areas and the open ocean.

The bias-corrected MODIS over ocean AOT and AE observations can be used for model validation or data assimilation. Our own interest is in the estimation of aerosol emissions from remote sensing observations (Schutgens et al., 2012). This bias correction also has consequences for the global aerosol distribution. Global maps of multi-year averaged bias-corrected AOT and AE show that far less fine mode particles are transported across the oceans than the original MODIS product suggests.

\section{Appendix A}

\section{MODIS AOT and AE selection and correction}

\section{A1 Data selection for MODIS AOT and AE}

- Discard any MODIS pixel with the uncorrected $\tau_{550}>3$;

- discard any MODIS pixel with cloud fraction > 0.8;

- discard any MODIS pixel that has no neighbours; 
- discard any MODIS pixel whose standard error is larger than

- Terra: $0.003+0.036 \tau_{550}+0.023 \tau_{550}^{2}$;

- Aqua: $0.002+0.040 \tau_{550}+0.021 \tau_{550}^{2}$;

- discard any MODIS pixel with SZA $<20^{\circ}$;

- discard any MODIS pixel for which $\mathrm{RH}<0.2$ and $T<260 \mathrm{~K}$.

Here $\tau_{550}$ is the MODIS AOT at $550 \mathrm{~nm}$ and SZA the solar zenith angle. RH is the relative humidity and $T$ is the temperature, both at $2 \mathrm{~m}$ above surface (NCEP-DOE-II).

\section{A2 Correction for MODIS AOT}

The following equations should be processed sequentially, like FORTRAN computer code.

If Terra $\tau_{550} \leq 0.049$ then

$$
\begin{aligned}
\tau_{550} & =(1+0.181581-0.0168456 w) \tau_{550} \\
\tau_{550} & =\left(\tau_{550}-0.0287665\right) / 0.243752 \\
\tau_{550} & =\tau_{550}+0.0207946-0.000153499 \Theta \\
\tau_{550} & =\left(1-0.364205-0.100776 f_{\mathrm{c}}\right) \tau_{550} \\
\tau_{550} & =(1.0-0.0822829+0.0781099 \alpha) \tau_{550} .
\end{aligned}
$$

If Terra $\tau_{550}>0.049$ then

$$
\begin{aligned}
& \tau_{550}=\tau_{550}-0.0122103-0.0358403 f_{\mathrm{c}} \\
& \tau_{550}=\tau_{550}+0.0320079-0.000243895 \Theta \\
& \tau_{550}=\tau_{550}-0.0294600+0.0266009 \alpha \\
& \tau_{550}=\left(\tau_{550}-0.0142035\right) / 0.898996 \\
& \tau_{550}=\tau_{550}+0.00378178-0.000665484 w .
\end{aligned}
$$

If Aqua $\tau_{550} \leq 0.05$ then

$$
\begin{aligned}
& \tau_{550}=(1+0.315863-0.0306199 w) \tau_{550} \\
& \tau_{550}=\left(\tau_{550}-0.0271628\right) / 0.301162 \\
& \tau_{550}=\tau_{550}+0.00514700-0.0274383 f_{\mathrm{c}} \\
& \tau_{550}=(1-0.350973+0.0378387 \alpha) \tau_{550} .
\end{aligned}
$$

If Aqua $\tau_{550}>0.05$ then

$$
\begin{aligned}
& \tau_{550}=(1-0.258509+0.164087 \alpha) \tau_{550} \\
& \tau_{550}=\left(\tau_{550}-0.0328901\right) / 0.760698 \\
& \tau_{550}=\tau_{550}+0.00646153-0.0322341 f_{\mathrm{c}} \\
& \tau_{550}=\tau_{550}+0.0106865-0.00186725 \mathrm{w},
\end{aligned}
$$

where $\alpha$ is the uncorrected MODIS AE, $\Theta$ the scattering angle, $w$ the NCEP-DOE-II $10 \mathrm{~m}$ wind speed and $f_{\mathrm{c}}$ the cloud fraction.

\section{A3 Additional selection criterium for $\mathbf{A E}$}

For $\mathrm{AE}$ we use an additional selection criterium that optimizes the agreement between the original MODIS and AERONET AE

- Aqua: $\tau_{860} \geq 0.055$;

- Terra: $\tau_{860} \geq 0.057$

where $\tau_{860}$ is the (uncorrected) MODIS AOT at $860 \mathrm{~nm}$.

\section{A4 Correction for MODIS AE}

The following equations should be processed sequentially, like FORTRAN computer code.

If Terra $\tau_{550} \leq 0.083$ then

$$
\begin{aligned}
& \alpha=\alpha+0.239255+0.0181123 w \\
& \alpha=(\alpha-0.640555) / 0.229146 \\
& \alpha=\alpha+1.00041-0.00732544 \Theta .
\end{aligned}
$$

If Terra $\tau_{550}>0.083$ then

$$
\begin{aligned}
& \alpha=\alpha+0.423368-0.00279822 \Theta \\
& \alpha=(\alpha-0.334271) / 0.667072 \\
& \alpha=\alpha-0.128672+0.0246823 w .
\end{aligned}
$$

If Aqua $\tau_{550} \leq 0.087$ then

$$
\begin{aligned}
& \alpha=(\alpha-0.404072) / 0.278597 \\
& \alpha=(1.0+0.200161-0.00561571 \Theta) \alpha \\
& \alpha=\alpha+0.155928+0.0268758 w .
\end{aligned}
$$

If Aqua $\tau_{550}>0.087$ then

$\alpha=(\alpha-0.429633) / 0.586594$

$\alpha=\alpha-0.166538+0.0317318 w$

$\alpha=\alpha+0.101102-0.000775233 \Theta$

where $\tau_{550}$ is the uncorrected MODIS AOT, $\Theta$ the scattering angle, $w$ the NCEP-DOE-II $10 \mathrm{~m}$ wind speed and $f_{\mathrm{c}}$ the cloud fraction.

\section{A5 Random error in MODIS AOT}

For Terra, the random error in AOT at $550 \mathrm{~nm}$ can be modelled with

$$
\begin{aligned}
\epsilon= & 0.045-\tau_{550} e^{-\frac{\tau_{550}}{0.045}}+0.24\left(\tau_{550}^{2}-0.045^{2}\right) \\
& \left(1-e^{-\frac{\tau_{550}}{0.045}}\right)+0.0125 f_{\mathrm{c}} \\
& + \begin{cases}0 & \text { if } w \leq 8 \mathrm{~m} \mathrm{~s}^{-1} \\
0.003(w-8) & \text { if } w>8 \mathrm{~m} \mathrm{~s}^{-1}\end{cases}
\end{aligned}
$$


For Aqua, the random error in AOT at $550 \mathrm{~nm}$ can be modelled with

$$
\begin{aligned}
\epsilon= & 0.0425-1.25 \tau_{550} e^{-\frac{\tau_{550}^{0.525}}{0.25}}+\left(0.25\left(\tau_{550}^{2}-.0325^{2}\right)\right) \\
& \left(1-e^{\left.-\frac{\tau_{550}}{0.0325}\right)+0.0125 f_{\mathrm{c}}}\right. \\
& + \begin{cases}0 & \text { if } w \leq 8 \mathrm{~m} \mathrm{~s}^{-1} \\
0.0035(w-8) & \text { if } w>8 \mathrm{~m} \mathrm{~s}^{-1},\end{cases}
\end{aligned}
$$

where $\tau_{550}$ is the corrected MODIS AOT (see Sect. 7), $w$ the NCEP-DOE-II $10 \mathrm{~m}$ wind speed and $f_{\mathrm{c}}$ the cloud fraction.

\section{A6 Random error in MODIS AE}

For Terra, the random error in AE is reasonably well described by

$\epsilon=0.25+0.06 \alpha+\exp \left(-3.75 \sqrt{\tau_{550}}\right)$.

For Aqua, the random error in AE is reasonably well described by

$\epsilon=0.25+0.08 \alpha+\exp \left(-5 \sqrt{\tau_{550}}\right)$,

where $\tau_{550}$ is the corrected MODIS AOT and $\alpha$ the corrected MODIS AE (see Sect. 7).

Acknowledgements. We thank the relevant PIs and their staff for establishing and maintaining the AERONET sites used in this investigation. The NASA MODIS team is acknowledged for preparing and making available MODIS observations. NCEP Reanalysis 2 data was provided by the NOAA/OAR/ESRL PSD, Boulder, Colorado, USA, from their Web site at http://www.esrl.noaa.gov/psd. We also would like to thank Jeff Reid, Edward Hyer and two anonymous reviewers for their extensive and thoughtful comments that helped improve this paper. Part of this research was supported by funds from MOE/GOSAT, MOE/GER fund A1101, JST/CREST/EMS/TEEDDA, JAXA/EarthCARE and GCOM-C, MEXT/VL for climate diagnostics, MEXT/RECCA/SALSA, MEXT/KAKENHI/Innovative Areas 2409. The majority of this work was done while the first author was employed at AORI, University of Tokyo, Japan.

Edited by: O. Torres

\section{References}

Adames, A. F., Reynolds, M., Smirnov, A., Covert, D. S., and Ackerman, T. P.: Comparison of Moderate Resolution Imaging Spectroradiometer ocean aerosol retrievals with ship-based Sun photometer measurements from the Around the Americas expedition, J. Geophys. Res., 116, D16303, doi:10.1029/2010JD015440, 2011.

Anderson, T. L., Charlson, R. J., Winker, D. M., Ogren, J. A., and Holmen, K..: Mesoscale Variations of Tropospheric Aerosols, J. Atmos. Sci., 60, 119-136, 2003.
Anderson, T. L., Wu, J., Chu, D. A., Schmid, B., Redemann, J., and Dubovik, O.: Testing the MODIS satellite retrieval of aerosol fine mode fraction, J. Geophys. Res., 110, D18204, doi:10.1029/2005JD005978, 2005.

Bréon, F.-M., Vermeulen, A., and Descloitres, J.: An evaluation of satellite aerosol products against sunphotometer measurements, Remote Sens. Environ., 115, 3102-3111, doi:10.1016/j.rse.2011.06.017, 2011.

Eck, T. F., Holben, B. N., Reid, J. S., Dubovik, O., Smirnov, A., Neill, N. T. O., Slutsker, I., and Kinne, S.: Wavelength dependence of optical depth of biomass burning, urban and desert dust aerosols, J. Geophys. Res., 104, 31333-31349, 1999.

Holben, B. N., Eck, T. F., Slutsker, I., Tanre, D., Buis, J. P., Setzer, A., Vermote, E., Reagan, J. A., Kaufman, Y. J., Nakajima, T., Lavenu, F., Jankowiak, I., and Smirnov, A.: AERONET - A Federated Instrument Network and Data Archive for Aerosol Characterization, Remote Sens. Environ., 66, 1-16, doi:10.1016/S0034-4257(98)00031-5, 1998.

Huang, J., Hsu, N. C., Tsay, S.-C., Jeong, M.-J., Holben, B. N., Berkoff, T. A., and Welton, E. J.: Susceptibility of aerosol optical thickness retrievals to thin cirrus contamination during the BASE-ASIA campaign, J. Geophys. Res., 116, D08214, doi:10.1029/2010JD014910, 2011.

Hyer, E. J., Reid, J. S., and Zhang, J.: An over-land aerosol optical depth data set for data assimilation by filtering, correction, and aggregation of MODIS Collection 5 optical depth retrievals, Atmos. Meas. Tech., 4, 379-408, doi:10.5194/amt-4-379-2011, 2011.

Ichoku, C., Chu, D. A., Mattoo, S., Kaufman, Y. J., Remer, L. A., Tanre, D., Slutsker, I., and Holben, B. N.: A spatio-temporal approach for global validation and analysis of MODIS aerosol products, Geophys. Res. Lett., 29, 1616-1619, doi:10.1029/2001GL013206, 2002.

Ichoku, C., Remer, L., and Eck, T.: Quantitative evaluation and intercomparison of morning and afternoon Moderate Resolution Imaging Spectroradiometer (MODIS) aerosol measurements from Terra and Aqua, J. Geophys. Res., 110, D10S03, doi:10.1029/2004JD004987, 2005a.

Ichoku, C., Remer, L., and Eck, T.: Correction to "Quantitative evaluation and intercomparison of morning and afternoon Moderate Resolution Imaging Spectroradiometer (MODIS) aerosol measurements from Terra and Aqua?", J. Geophys. Res., 110, D10S99, doi:10.1029/2005JD005897, 2005b.

Kalnay, E., Kanamitsu, M., Kistler, R., Collins, W., Deaven, D., Gandin, L., Iredell, M., Saha, S., White, G., Woolen, J., Zhu, Y., Chelliah, M., Ebisuzaki, W., Higgins, W., Janowiak, J., Mo, K. C., Ropelewski, C., Wang, J., Leetmaa, A., Reynolds, R., Jenne, R., and Joseph, D.: The NCEP/NCAR 40-year reanalysis project, B. Amer. Meteorol. Soc., 77, 437-471, 1996.

Kanamitsu, M., Ebisuzaki, W., Woollen, J., Yang, S.-K., Hnilo, J. J., Fiorino, M., and Potter, G. L.: NCEP-DEO AMIP-II Reanalysis (R-2), B. Am. Meteorol. Soc., 83, 1631-1643, 2002.

Kleidman, R. G., O’Neill, N. T., Remer, L. A., Kaufman, Y. J., Eck, T. F., Tanré, D., Dubovik, O., and Holben, B. N.: Comparison of Moderate Resolution Imaging Spectroradiometer (MODIS) and Aerosol Robotic Network (AERONET) remote-sensing retrievals of aerosol fine mode fraction over ocean, J. Geophys. Res., 110, D22205, doi:10.1029/2005JD005760, 2005. 
Kovacs, T.: Comparing MODIS and AERONET aerosol optical depth at varying separation distances to assess ground-based validation strategies for spaceborne lidar, J. Geophys. Res., 111, D24203, doi:10.1029/2006JD007349, 2006.

Liu, H. and Pinker, R. T.: Radiative fluxes from satellites: Focus on aerosols, J. Geophys. Res., 113, D08208, doi:10.1029/2007JD008736, 2008.

Mishchenko, M. I., Geogdzhayev, I. V., Liu, L., Lacis, A. a., Cairns, B., and Travis, L. D.: Erratum to "Toward unified satellite climatology of aerosol properties: What do fully compatible MODIS and MISR aerosol pixels tell us?" [Journal of Quantitative Spectroscopy and Radiative Transfer 110 (2009) 402-408], J. Quant. Spectrosc. Ra., 110, 1962-1963, doi:10.1016/j.jqsrt.2009.05.015, 2009.

Mishchenko, M. I., Liu, L., Geogdzhayev, I. V., Travis, L. D., Cairns, B., and Lacis, A. A.: Toward unified satellite climatology of aerosol properties, Journal of Quantitative Spectroscopy and Radiative Transfer, 111, 540-552, doi:10.1016/j.jqsrt.2009.11.003, 2010.

Remer, L. A., Tanre, D., Kaufman, Y. J., Ichoku, C., Mattoo, S., Levy, R., Chu, D. A., Holben, B., Dubovik, O., Smirnov, A., Martins, J. V., Li, R., and Ahmad, Z.: Validation of MODIS aerosol retrieval over ocean, Geophys. Res. Lett., 29, 2-5, 2002.

Remer, L. A., Kaufman, Y., Tanre, D., Mattoo, S., Chu, D., Martins, J., Li, R.-R., Ichoku, C., Levy, R., Kleidman, R., Eck, T., Vermote, E., and Holben, B.: The MODIS Aerosol Algorithm, Products, and Validation, J. Atmos. Sci., 62, 947-973, 2005.

Remer, L. A., Kleidman, R. G., Levy, R. C., Kaufman, Y. J., Tanré, D., Mattoo, S., Martins, J. V., Ichoku, C., Koren, I., Yu, H., and Holben, B. N.: Global aerosol climatology from the MODIS satellite sensors, J. Geophys. Res., 113, D14S07, doi:10.1029/2007JD009661, 2008.

Santese, M., De Tomasi, F., and Perrone, M. R.: AERONET versus MODIS aerosol parameters at different spatial resolutions over southeast Italy, J. Geophys. Res., 112, D10214, doi:10.1029/2006JD007742, 2007.

Schmid, B., Michalsky, J., Halthore, R., Beauharnois, M., Harnson, L., Livingston, J., Russell, P., Holben, B., Eck, T., and Smirnov, A.: Comparison of Aerosol Optical Depth from Four Solar Radiometers During the Fall 1997 ARM Intensive Observation Period, Geophys. Res. Lett., 26, 2725-2728, 1999.
Schutgens, N., Nakata, M., and Nakajima, T.: Estimating Aerosol Emissions by Assimilating Remote Sensing Observations into a Global Transport Model, Remote Sens., 4, 3528-3543, doi:10.3390/rs4113528, 2012.

Shi, Y., Zhang, J., Reid, J. S., Holben, B., Hyer, E. J., and Curtis, C.: An analysis of the collection 5 MODIS over-ocean aerosol optical depth product for its implication in aerosol assimilation, Atmos. Chem. Phys., 11, 557-565, doi:10.5194/acp-11-557-2011, 2011.

Shinozuka, Y. and Redemann, J.: Horizontal variability of aerosol optical depth observed during the ARCTAS airborne experiment, Atmos. Chem. Phys., 11, 8489-8495, doi:10.5194/acp-11-84892011, 2011.

Smirnov, A., Holben, B. N., Giles, D. M., Slutsker, I., O’Neill, N. T., Eck, T. F., Macke, A., Croot, P., Courcoux, Y., Sakerin, S. M., Smyth, T. J., Zielinski, T., Zibordi, G., Goes, J. I., Harvey, M. J., Quinn, P. K., Nelson, N. B., Radionov, V. F., Duarte, C. M., Losno, R., Sciare, J., Voss, K. J., Kinne, S., Nalli, N. R., Joseph, E., Krishna Moorthy, K., Covert, D. S., Gulev, S. K., Milinevsky, G., Larouche, P., Belanger, S., Horne, E., Chin, M., Remer, L. A., Kahn, R. A., Reid, J. S., Schulz, M., Heald, C. L., Zhang, J., Lapina, K., Kleidman, R. G., Griesfeller, J., Gaitley, B. J., Tan, Q., and Diehl, T. L.: Maritime aerosol network as a component of AERONET - first results and comparison with global aerosol models and satellite retrievals, Atmos. Meas. Tech., 4, 583-597, doi:10.5194/amt-4-583-2011, 2011.

Tanre, D., Kaufman, Y. J., Herman, M., and Mattoo, S.: Remote sensing of aerosol properties over ocean using the MODIS/EOS spectral radiances, J. Geophys. Res., 102, 16971-16988, 1997.

Zhang, J. and Reid, J. S.: MODIS aerosol product analysis for data assimilation: Assessment of over-ocean level 2 aerosol optical thickness retrievals, J. Geophys. Res., 111, D22207, doi:10.1029/2005JD006898, 2006. 